\title{
Tailored synthesis of nanostructured WC/a-C coatings by dual magnetron sputtering
}

\author{
M.D. Abad, M.A. Muñoz-Márquez, S. El Mrabet, A. Justo, J.C. Sánchez-López* \\ Instituto de Ciencia de Materiales de Sevilla (Centro Mixto CSIC-Universidad de Sevilla), \\ Avda. Américo Vespucio 49, 41092-Sevilla, Spain
}

\begin{abstract}
Nanostructured coatings with variable contents of tungsten carbide (WC) and amorphous carbon $(\mathrm{a}-\mathrm{C})$ are prepared by controlling the sputtering power ratio using WC and graphite targets. XRD and TEM/ED analysis shows that increasing the C incorporation, the $\mathrm{WC}$ nanocrystalline phases evolve from $\gamma-\mathrm{W}_{2} \mathrm{C}$ to $\beta-\mathrm{WC}_{1-\mathrm{x}}$. Further $\mathrm{C}$ enrichment leads to a nanocomposite structure of small $\mathrm{WC}_{1-\mathrm{x}}$ crystals dispersed in a-C matrix. The a-C at.\% is estimated by XPS analysis and correlated with the observed tribo-mechanical properties. The hardness and friction properties vary from hard/high friction (36-40 GPa; $\mu=0.6-0.8)$ to moderate-hard/low friction (16-20 GPa; $\mu \sim 0.2)$ coatings depending on the film composition. The transition point is found for a-C content of 10 at. $\%$. This correlates with a change from nanocrystalline WC to nanocomposite $\mathrm{WC}_{1-\mathrm{x}} / \mathrm{a}-\mathrm{C}$ coatings. The overall study will help to understand the previous literature data and will serve as guide for a tailored synthesis of these WC/a-C nanocomposites.
\end{abstract}

Keywords: Tungsten carbide; amorphous carbon; nanocomposites; friction; magnetron sputtering; hardness

*Corresponding author details:

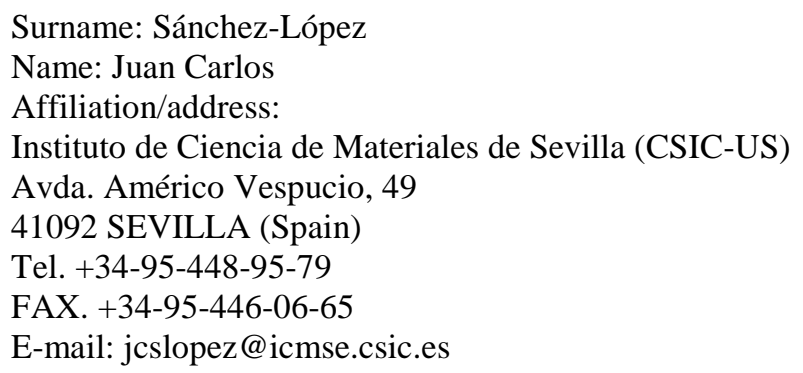




\section{Introduction}

Tungsten-carbon hard coatings are widely used as protective coatings due to its high melting temperature, high hardness, relatively low conductivity and excellent chemical stability [1-6]. To improve their practical performance and durability in load bearing, rolling sliding contact applications other properties as high toughness or reduced friction are of interest as well $[7,8]$. The combination of a hard tungsten carbide phase with ductile phases such as carbon has been assessed in the form of multilayer or nanocomposite coatings as a good approach to achieve this advanced functionality mixing the best properties from both materials [4,9-13]. Moreover, the possibilities that the nanostructuration offers for obtaining materials with improved properties by appropriate control of the chemical composition and microstructure at the nanoscale, boost the development of new multiphase coatings with designed architecture $[14,15]$. The nature of the components, crystal size and the amount of each phase determines the final properties of the material [16-18].

By way of example, the $\mathrm{WC} / \mathrm{C}$ multilayered coating used in commercial gear applications that increases the load carrying capacity, reduces friction and fuel consumption by controlling the periodicity of the multilayer structure [19-21]. Another way to improve the WC coatings performance is the formation of the so-called nanocomposite structure, consisting of a high density of nanometer sized crystals embedded in an amorphous carbon or DLC matrix [8-12,22,23]. Comparing the tribological properties of $\mathrm{WC} / \mathrm{C}$ in multilayered and nanocomposite forms, the more homogeneous dispersion of WC nanocrystallites throughout the $\mathrm{W}-\mathrm{C}: \mathrm{H}$ layer provides better abrasive wear resistance, while the multilayered form performs better in the impact fatigue tests [20]. Another well-known example corresponds to the 
$\mathrm{WC} / \mathrm{DLC} / \mathrm{WS}_{2}$ nanocomposite system, which is formed by nanometric grains of WC and $\mathrm{WS}_{2}$ grains embedded in an amorphous DLC matrix. This system operates as a lubricant in aerospace applications involving environmental changes from ambient air to vacuum $[24,25]$.

The deposition of tungsten carbide films has been done by many chemical vapour deposition (CVD) [26-29] and physical vapour deposition (PVD) methods [3,4,7-12,30-37]. Focusing in PVD technique, different options have been tried namely: non reactive magnetron sputtering of $\mathrm{WC}$ target $[30,31]$; reactive magnetron sputtering of W or WC with $\mathrm{CH}_{4}[3,22,32], \mathrm{C}_{2} \mathrm{H}_{2}[7,11,12,33,34], \mathrm{C}_{2} \mathrm{H}_{4}$ [35], benzene [23] or fullerene [36]; the simultaneous sputtering of tungsten and carbon targets [37] or by laser ablation of graphite alternatively [8-10]. One of the main peculiarities of the WC material is the high number of compositional and structural forms that can exist according to the W-C phase diagram [38-40]. The determination of the crystalline phases, grain size, and concentration with respect to the amorphous carbon are crucial to make a tailored synthesis and to establish a correlation with the final properties (mechanical, tribological and/or thermal stability). Despite many authors have studied this system, just a few publications have tried to quantify the relative amount of amorphous carbon. This lack of results may be due to the wide range of nonstoichometric W-C phases and the absence of long-range crystal order.

In this work, we detail a novel approach for depositing WC/a-C nanocomposite coatings by direct non-reactive sputtering of $\mathrm{WC}$ and $\mathrm{C}$ targets with argon. By changing the sputtering power applied to each target, a series of coating is prepared where the proportion between nanocrystalline tungsten carbide and amorphous carbon are tailored. The characterization is carried out by different spectroscopic and microscopic techniques with the aim of determining the characteristic features and distribution of 
both phases inside the nanocomposite. XRD, TEM, HR-TEM and ED techniques are used for investigating the crystalline phases while XPS and Raman spectroscopy for characterising the carbon phase as a function of the film deposition parameters. With the obtained information it is possible to correlate synthesis parameters, film structure, and phase composition (WC/a-C) with the physical properties such as tribological, mechanical and thermal stability. This complete study will help to understand the previous literature reported on this system and will serve as guide for a tailored synthesis of these materials with the desired properties depending on the foreseen application.

\section{Experimental details}

WC/a-C coatings were prepared by Ar sputtering of WC (Kurt J. Lesker, 99.5\% purity) and graphite (Goodfellow, 99.5\% purity) targets connected to radio frequency (r.f.) and direct current (d.c.) power sources respectively. A series of samples has been prepared by changing the sputtering power ratio, defined as $\mathrm{R}=\mathrm{P}_{\mathrm{C}} / \mathrm{P}_{\mathrm{WC}}$, from 0 to 3 . The typical power values $\left(\mathrm{P}_{\mathrm{WC}}\right)$ applied to the $\mathrm{WC}$ target were 150 and $250 \mathrm{~W}$ while those applied to the graphite target $\left(\mathrm{P}_{\mathrm{C}}\right)$ were varied from 0 to $450 \mathrm{~W}$. The obtained films are labelled as R0, R0.1, R0.3, R0.5, R1, R2 and R3. In all cases, an underlayer was previously deposited by sputtering exclusively the WC target at $250 \mathrm{~W}$ whilst the substrates were negatively biased with a d.c. source at 100V (conditions corresponding to R0 film). The pressure of the reaction chamber was about $3 \times 10^{-4} \mathrm{~Pa}$ before deposition and $0.60 \mathrm{~Pa}$ while growing. The substrate materials were $\mathrm{Si}(100), \mathrm{NaCl}$ and M2 steel depending on the characterization technique. They were mounted on a rotary sample-holder $(10 \mathrm{rpm})$ situated at $10 \mathrm{~cm}$ from the targets. No external heating was 
applied to the substrates although the temperature was found to vary in the range of $150-200^{\circ} \mathrm{C}$ due to the heating effect of the plasma. Typical film growth times were about 4 hours and film thicknesses range from 0.75 to $2.5 \mu \mathrm{m}$ as measured by means of a stylus profilometer.

The X-ray photoelectron spectroscopy (XPS) data were recorded in a VGEscalab 210 spectrometer working in constant analyzer energy mode at a pass energy of $50 \mathrm{eV}$ and non-monochromatic $\mathrm{Mg} \mathrm{K}(\mathrm{hv}=1253.6 \mathrm{eV})$ radiation as excitation source. Samples were previously cleaned using $\mathrm{Ar}^{+}$ion bombardment with an energy of 2.5 $\mathrm{keV}$, the sputtering was kept for $300 \mathrm{~s}$ with a nominal drain current of $1.7 \mu \mathrm{A} / \mathrm{cm}^{2}$ and an $\mathrm{Ar}$ partial pressure of $2.5 \times 10^{-3} \mathrm{~Pa}$. These conditions were found to be the most appropriate to remove preferentially the largest possible amount of hydrocarbon surface contamination layer without affecting the film elemental composition as checked in consecutive survey scans. Quantification was accomplished by determining the elemental peak areas, following a Shirley background subtraction and Voigt functions corrected by the relative sensitivities of the elements using Scofield cross-sections. Fitting procedure was then carried by a least squares routine using XPS Peak Fitting Programme 4.1 [41] on the W 4f, $\mathrm{C}$ 1s and $\mathrm{O}$ 1s photoelectron peaks.

Raman spectra measurements $\left(200-2000 \mathrm{~cm}^{-1}\right)$ were carried out in a LabRAM Horiba Jobin Yvon spectrometer equipped with a CCD detector and a He-Ne laser (532 $\mathrm{nm})$ at $5 \mathrm{~mW}$. All the samples were analyzed during $150 \mathrm{~s}$ of exposure time and an aperture hole of $100 \mu \mathrm{m}$. Continuous recording of the spectra allows the detection of any eventual laser-induced transformation. The spectra displayed in the figures were subjected to neither normalisation nor background subtraction.

The crystal structure of the films was examined by grazing angle X-ray diffraction analysis (GIXRD) using $\mathrm{Cu} \mathrm{K}_{\alpha}$ radiation $(1.54 \AA$ ) in a Siemens D5000 
diffractometer at an incidence angle of $1^{\circ}$ in order to increase the signal from the coating compared with the substrate.

Transmission electron microscopy (TEM), high resolution transmission electron microscopy (HRTEM) and electron diffraction (ED) analyses were carried out in a Philips CM200 microscope operating at $200 \mathrm{kV}$. Energy-filtering transmission electron microscopy (EFTEM) was performed in a Tecnai F20 at 200kV field emission gun (FEG). For their observation, the films were grown on $\mathrm{NaCl}$ substrates and then floated off in water and supported on a carbon coated copper grid. Scanning electron microscopy (SEM) data were recorded in a FEG Hitachi S4800 microscope operating at $5 \mathrm{kV}$

The thermal stability of samples was studied by using a high temperature chamber attached to an X-ray diffraction apparatus. The specimen is placed lying on a ceramic holder made of alumina. The measurements were performed by using a Philips PW 3040/60 vertical goniometer with monochromatic $\mathrm{Cu} \mathrm{K}_{\alpha}(0.154 \mathrm{~nm})$ radiation in $\theta / 2 \theta$ mode. All samples were heat treated under vacuum from room temperature up to $1100{ }^{\circ} \mathrm{C}$ at a temperature rate of $5{ }^{\circ} \mathrm{C} / \mathrm{min}$ with a base pressure of $0.1 \mathrm{~Pa}$.

Nanoindentation experiments were performed with a Nanoindenter II (Nano Instruments, Inc., Knoxville, TN) microprobe. All tests were carried out at room temperature with a diamond Berkovich (three-sided pyramid) indenter tip. The loaddisplacement data obtained were analysed using the method of Oliver and Pharr [42] to determine the hardness and the elastic modulus as a function of the displacement of the indenter. The maximum load was selected in such a way that the maximum indentation depth did not exceed $10-15 \%$ of the coating thickness in order to avoid the influence of the substrate. 
Tribological tests were carried out using AISI52100 6 mm-diameter steel balls in a pin-on-disk CSM tribometer with a sliding speed of $10 \mathrm{~cm} / \mathrm{s}$ and $5 \mathrm{~N}$ of applied load (maximum initial Herztian contact pressure of $1.12 \mathrm{GPa}$ ) in ambient air $(30-60 \%$ of relative humidity). The sliding distance was $1000 \mathrm{~m}$ with typical track radius between 6 and $10 \mathrm{~mm}$. Normalized wear rates $\left(\mathrm{mm}^{3} / \mathrm{Nm}\right)$ were evaluated from cross-sectional profiles taken across the disk-wear track after testing by means of stylus profilometry.

\section{Results and discussion}

\subsection{Chemical composition}

The synthesis conditions such as the power applied to each magnetron and the power ratio are summarized in Table 1 along with the chemical composition for the studied coatings. It is worth mentioning that WC sputtering power was set at $250 \mathrm{~W}$ from $\mathrm{R} 0$ to $\mathrm{R} 1$ and later reduced at $150 \mathrm{~W}$ for $\mathrm{R} 2$ and $\mathrm{R} 3$ in order to fulfil the power ratio with respect to the graphite within the limit specifications of the magnetron heads. The corresponding carbon power was varied between 0 and $450 \mathrm{~W}$ to maintain the power ratio from 0 to 3 . Fig. 1a shows the deposition rate of the coatings as a function of the power ratio. It can be noticed how the deposition rate increases almost linearly from R0 to R1 if the power applied to the WC target is kept constant. However, the diminution of $\mathrm{P}_{\mathrm{WC}}$ to $150 \mathrm{~W}$ yielded a drastic reduction of the deposition rate although it tends always to increase at higher power ratio.

Elemental chemical compositions of the coatings as determined by XPS are shown in Table 1 . The present data correspond to the surface state after cleaning with an $\mathrm{Ar}^{+}$ion bombardment. Fig. $1 \mathrm{~b}$ shows the variation of the $\mathrm{W}, \mathrm{C}$ and $\mathrm{O}$ atomic percentages versus power ratio. The average oxygen contamination remains low, 
typically in the range of 2 to 5 at.\% and its presence can be due to molecular oxygen desorbed from the chamber walls or contained as an impurity in the target and/or in the sputtering gas. The total carbon content in the films progressively increases from 33 to 71 at. $\%$ as the power ratio is changed from 0 to 3.

\subsection{Chemical bonding}

C 1s and W 4f XPS spectra for the series of the coatings are shown in Fig. 2a and b respectively. The $\mathrm{C} 1 \mathrm{~s}$ peak presents two main components at 283.5 and $285 \mathrm{eV}$ that can be ascribed to $\mathrm{C}-\mathrm{W}$ and $\mathrm{C}-\mathrm{C}$ bonds respectively. The relative contribution of the $\mathrm{C}$ $\mathrm{C}$ peak increases at higher $\mathrm{R}$ values corresponding to the formation of an amorphous $\mathrm{C}$ bonded (a-C) matrix. Regarding the $\mathrm{W} 4 \mathrm{f}$ photoelectron spectra, the main component $\mathrm{W}$ $4 \mathrm{f}_{7 / 2}$ is placed at around $31.5 \mathrm{eV}$ which indicates the existence of $\mathrm{W}-\mathrm{C}$ bonds. This binding energy tends to shift towards $32 \mathrm{eV}$ and the doublet peak to get broader as a consequence of the carbon enrichment [8]. Similar binding energies were found in other works $[8,11]$. In order to obtain a more quantitative insight of the compositional changes a fitting analysis was carried out in both peaks.

Fig. 3 displays all the different components considered in the fitting analysis of $\mathrm{C}$ 1s (a) and W 4f (b) XPS peaks before and after $\mathrm{Ar}^{+}$bombardment using the sample R1 (63 at.\% of C) as representative example. The $\mathrm{C} 1 \mathrm{~s}$ peak was fitted assuming main contributions from W-C $(283.5 \mathrm{eV})$, a-C $(285 \mathrm{eV})$, and C-O from surface contamination $(286.7 \mathrm{eV}$ and $288.6 \mathrm{eV})$. For the $\mathrm{W} 4 \mathrm{f}$ peak, besides the main component corresponding to $\mathrm{W}-\mathrm{C}$ bonds at $31.5 \mathrm{eV}$, a doublet $\mathrm{W} 4 \mathrm{f}$ for the $\mathrm{WO}_{3}$ at $35.7 \mathrm{eV}$ and the contributions from the W 5p peaks for each chemical species are considered. The fitting analysis enables to estimate the proportion of carbide/a-C inside the coatings and the 
$\mathrm{WC}_{\mathrm{x}}$ stoichiometry. The obtained values following a similar procedure are summarized in Table 1.

Fig. 4 illustrates the fraction of $\mathrm{C}$ bonded to $\mathrm{W}\left(\mathrm{C}_{\mathrm{C}-\mathrm{W}} / \mathrm{W}_{\mathrm{W}-\mathrm{C}}\right)$ (stoichiometry of $\mathrm{WC}_{\mathrm{x}}$ phases) and the fraction of total $\mathrm{C}$ with respect to the tungsten carbide phases $\left(\mathrm{C}_{\text {total }} / \mathrm{W}_{\mathrm{W}-\mathrm{C}}\right)$ (stoichiometry of $\mathrm{WC} / \mathrm{a}-\mathrm{C}$ nanocomposite). It can be noticed that from the R0.3 film, the content of free carbon increases above the carbide component. The variation of the $\mathrm{C} / \mathrm{W}$ ratio in this component from 0.4 to 1.3 indicates the formation of non-stoichiometric $\mathrm{WC}_{\mathrm{x}}$ phases. These results are not surprising since transition metal nitrides $[43,44]$ and carbides $[45,46]$ are rather non-stoichiometric materials and tend to easily incorporate significant vacancy concentrations on both the metal and non-metal sublattices. In substoichiometric carbides the most significant defect is the $\mathrm{C}$ vacancy while in C-rich compounds, although the presence of $\mathrm{W}$ vacancies cannot be ruled out completely, the excess $\mathrm{C}$ can form a metastable solid solution [23,36]. Other authors $[3,36]$ have observed as well high solubility of $\mathrm{C}$ (approx. 5-25 at.\%) by XPS in reactively sputtered $\mathrm{W}$ films; despite the solubility of carbon in $\alpha-\mathrm{W}$ is negligible at room temperature under equilibrium conditions (only $\approx 0.7$ at. $\%$ at $2715{ }^{\circ} \mathrm{C}$ ). This fact can explain the high concentration of $\mathrm{C}-\mathrm{W}$ bonds in the carbon-rich region by forming a metastable interstitial solid solution. The binding energy of this component would be similar to that of $\mathrm{C}$ in WC compounds and, therefore, undistinguishable contributing to the increment of the $\mathrm{C} / \mathrm{W}$ ratio [47].

The formation of an amorphous carbon bonded-matrix is confirmed by Raman spectroscopy (Fig. 5a). Only for samples with carbon content higher than 50 at.\%, the two peaks characteristic of the $\mathrm{sp}^{2}$ sites of all disordered carbons at 1350 (D-peak) and ordered graphite at $1585 \mathrm{~cm}^{-1}$ (G-peak) are clearly observed [48]. Identical results were found when the total carbon content exceeded the 48.8 at.\% by Czyzniewski [11] or 65 
at.\% by Voevodin et al. [8]. The main changes are noticed for power ratios R2 and R3. Fig. 5 b shows the variation of the $G$ peak and the relative intensity of $D$ and $G$ peaks for the samples containing a-C contents higher than 10 at. $\%$, when the peaks are discernible. The $\mathrm{G}$ position shifts downwards from $1572 \mathrm{~cm}^{-1}$ to $1550 \mathrm{~cm}^{-1}$ indicating an increased disorder of the $\mathrm{sp}^{2}$-bonded carbon structure. However, less sensitivity to changes is noticed from the $\mathrm{I}_{\mathrm{D}} / \mathrm{I}_{\mathrm{G}}$ ratio with the increment of the power ratio.

\subsection{Crystalline phase composition}

Tungsten carbide has a high number of compositional and structural forms. According to the W-C phase diagram [38], three different carbides are formed: the hexagonal stoichiometric monocarbide WC that melts incongruently; a face centered cubic (fcc) carbide $\beta-\mathrm{WC}_{1-\mathrm{x}}$ phase (where $0.34 \leq \mathrm{x} \leq 0.43$ ) with a $\mathrm{NaCl}$ structure; and a second hexagonal carbide $\mathrm{W}_{2} \mathrm{C}$ which presents four possible polymorphic modifications namely, low $(\alpha)$, intermediate $(\beta$ and $\varepsilon)$ and high-temperature $(\gamma)$. These four polymorphs differ in the ordering of the $\mathrm{C}$ atoms in the interstitial positions as demonstrated by a recent paper of Suetin et al. [39]. Both phases, $\beta-\mathrm{WC}_{1-\mathrm{x}}$ and $\mathrm{W}_{2} \mathrm{C}$ are stable from 1250 to $2500{ }^{\circ} \mathrm{C}$ respectively although hexagonal $\mathrm{WC}$ is the only thermodynamically stable phase at room temperature, metastability in the system has been reported in both concentration-driven and temperature-driven non-equilibrium transitions [49]. For instance, the metastable $\mathrm{WC}_{1-\mathrm{x}}$ and $\mathrm{W}_{2} \mathrm{C}$ are found to be formed as kinetic products from rapid cooling of $\mathrm{WC}$. These two phases $\mathrm{WC}_{1-\mathrm{x}}$ and $\mathrm{W}_{2} \mathrm{C}$ are also those often observed by sputtering, as previously shown $[8,23,30]$.

The X-ray diffraction patterns of the as-prepared WC/a-C films are shown in Fig. 6a in the region 20-80 $\left(2 \theta^{\circ}\right)$. Asymmetric and broad peaks are observed, indicating 
nanocrystallinity and lattice defects. Indeed, the main identified phases correspond to hexagonal $\mathrm{W}_{2} \mathrm{C}$ and cubic $\beta-\mathrm{WC}_{1-\mathrm{x}}$. No peaks from the hexagonal $\alpha-\mathrm{WC}$ are observed despite of using a pure WC target and being the only thermodynamically stable carbide phase in the $\mathrm{W}-\mathrm{C}$ system at room temperature. The crystalline character of the coatings decreases as the $\mathrm{R}$ parameter increases, becoming X-ray amorphous at the highest ratio. The increment of the power applied to the graphite target induces a reduction of the diffraction domain sizes, probably because carbon in excess makes the grain growth difficult [15].

In Fig. 6b, the diffractograms recorded in the region 30-50 $\left(2 \theta^{\circ}\right)$ of coatings R0, R0.1 and R0.3 are shown in detail. Initially, by single sputtering of the WC target (R0), the XRD shows a diffraction pattern that can be assigned to hexagonal $\mathrm{W}_{2} \mathrm{C}$ phase. In the four $\mathrm{W}_{2} \mathrm{C}$ polymorphs $(\alpha, \beta, \varepsilon$ and $\gamma)$, the $\mathrm{W}$ atoms form an hexagonal close packed (hcp) sublattice in which half of the octahedral interstices are occupied by carbon atoms. Depending on the arrangement of carbon atoms, $\mathrm{W}_{2} \mathrm{C}$ may be disordered (at high temperatures) or ordered (at low temperatures). The low-temperature phase $\alpha-\mathrm{W}_{2} \mathrm{C}$ has a hexagonal structure with carbon ordering and the high-temperature phase $\gamma-\mathrm{W}_{2} \mathrm{C}$ a hexagonal structure with a disordered arrangement of carbon atoms and vacancies. The XRD patterns of the these four polymorphs differ very little because these phases have the same hexagonal tungsten sublattice, whereas the atomic scattering factor of carbon is many times lower than that of tungsten. For this reason, changes in the arrangement of carbon atoms in $\mathrm{W}_{2} \mathrm{C}$ are only detectable at low diffraction angles $\left(2 \theta^{\circ}<30\right)$. The polymorphs $\alpha-\mathrm{W}_{2} \mathrm{C}, \beta-\mathrm{W}_{2} \mathrm{C}$ and $\varepsilon-\mathrm{W}_{2} \mathrm{C}$ present some peaks at these low angles whilst none can be found for the $\gamma-\mathrm{W}_{2} \mathrm{C}$ [39]. A closer view of the GIXRD diagram at these low angles is shown for R0 sample in the inset of Fig. 6b. The total absence of peaks in this region is thus indicative of the $\gamma-\mathrm{W}_{2} \mathrm{C}$ phase. Palmquist et al. also concluded the 
formation of this same phase using C60 as carbon precursor [36]. This high temperature structure with a disordered arrangement of carbon atoms and vacancies is probably reached because of the non-equilibrium conditions of the plasma sputtering processes.

In the GIXRD diffractogram of the R0 sample, the (100) diffraction peak at $34.5^{\circ}$ and an intense peak at around $39^{\circ}$ originated by the overlapping of the (002) and (101) planes are identified. Ignoring any possible strain broadening contribution, estimations of the grain size was done by means of the Scherrer's formula. From the broadening of these peaks an average crystallite size of $9 \mathrm{~nm}$ was estimated. The next sample R0.1 exhibits an additional peak located at about $42^{\circ}$ attributed to the (200) reflection peak of the cubic $\beta-\mathrm{WC}_{1-\mathrm{x}}$ phase, while the overlapped intensity of the $(002 / 101)$ planes of the $\gamma-\mathrm{W}_{2} \mathrm{C}$ phase is reduced. These results suggest that the R0.1 film is a double phase film containing hexagonal $\gamma-\mathrm{W}_{2} \mathrm{C}$ and $\beta-\mathrm{WC}_{1-\mathrm{x}}$ phases. The crystallite size in $\gamma-\mathrm{W}_{2} \mathrm{C}$ was reduced to about $7 \mathrm{~nm}$ while the $\beta-\mathrm{WC}_{1-\mathrm{x}}$ crystallite size is estimated to be about $5 \mathrm{~nm}$. In contrast, for higher R values, the diffraction patterns of the associated films exhibit mainly a broad peak located at about $37.5^{\circ}$ which can be associated to the (111) reflection peak of the fcc $\beta-\mathrm{WC}_{1-\mathrm{x}}$ phase. A rough estimation of the crystalline grain size gives a value of $2-3 \mathrm{~nm}$. These results, taking into account the range of carbon contents cited in Table 1, are in good agreement with previous works $[37,49]$ where a transition from $\gamma-\mathrm{W}_{2} \mathrm{C}$ to $\beta-\mathrm{WC}_{1-\mathrm{x}}$ is observed at a carbon content of $35-$ 40 at.\%. Further increment, above 45 at.\%, results in XRD amorphous films with a weak and broad peak at $37.5^{\circ}$ assigned to $\mathrm{WC}_{1-\mathrm{x}}(111)$ planes. Hereafter, we will use the general form $\mathrm{W}_{2} \mathrm{C}$ and also $\mathrm{WC}_{1-\mathrm{x}}$ without specifying the crystallographic structure here determined.

\subsection{Microstructure}


The results of the X-ray diffraction experiments are further confirmed by TEM. Fig. 7 shows four representative planar-view TEM micrographs of coatings prepared at growing ratios (R0, R0.1, R0.5 and R3) together with their associated electron diffraction patterns. The microstructure is formed by small grains of 5-10 nm in the samples $\mathrm{R} 0$ and $\mathrm{R} 0.1$, however, these features vanish at $\mathrm{R} \geq 0.5$. The presence of welldefined electron diffraction rings is noticed for the lowest power ratios while they become more diffuse when the power ratio increases. These results are in agreement with a more disordered $\mathrm{WC}_{1-\mathrm{x}}$ phase and a progressive enrichment in amorphous carbon matrix.

Fig. 8 shows two pictures at higher magnifications of the coatings R0.1 and R1 together with their associated ED patterns confirming the nanocrystalline character although with different microstructure. Thus, R0.1 can be defined as a polycrystalline sample formed by small crystalline domains whilst R1 is a nanocomposite of small crystals embedded in an amorphous matrix. Focusing on the sample R0.1, the interplanar distances of $2.1,2.2$ and $2.4 \AA$ can be measured corresponding to (200) $\mathrm{WC}_{1-\mathrm{x}}$, (101) $\mathrm{W}_{2} \mathrm{C}$ and (111) $\mathrm{WC}_{1-\mathrm{x}}$, crystal planes respectively, corroborating the mixture of phases. Moreover, the indexation of the ED rings is in agreement with a mixture of $\mathrm{W}_{2} \mathrm{C}$ and $\mathrm{WC}_{1-\mathrm{x}}$ phases. In the $\mathrm{R} 1$ sample, it is distinguished a small crystal about 3-4 $\mathrm{nm}$ in diameter with a interplanar distance of $2.4 \AA$ characteristic of the $\mathrm{WC}_{1-\mathrm{x}}$ (111) family of planes. The analysis of the diffraction rings for this sample leads to interplanar distances of $2.4,1.5$ and $1.3 \AA$. These values can be correlated with the family of planes (111), (220) and (311) of $\mathrm{WC}_{1-\mathrm{x}}$ crystalline phase.

Fig. 9 contains four fracture cross-sections of the coatings R0, R0.1, R1 and R2 examined by SEM as representative pictures of the different film morphologies. The underlayer of about $0.35 \mu \mathrm{m}$ is only visible for the highest power ratios where the 
differences in chemical and structure are more evident. Fig. 9a corresponds to the R0 sample and is characterized by a dense structure. This sample was grown with a negative polarisation of the substrate $(100 \mathrm{~V}$ d.c. $)$ that induces ion bombardment during the growth process. This ion bombardment controls the microstructure directly by resputtering and increases diffusivity of the adatoms as a consequence of both the increment in the substrate temperature and direct momentum transfer [30]. It is known that through these mechanisms ion bombardment inhibits columnar growth and preferential nucleation respectively [50,51]. In the next case (Fig. 9b), with a slight variation in the power ratio (R0.1) and the absence of bias, the development of a fine columnar structure is observed. By further increase of the carbon content, in the R1 sample, this microstructure becomes glassy-like or fine-grained and can be correlated to small nanocrystals of $\mathrm{WC}_{1-\mathrm{x}}$ in a matrix of a-C [11,34]. A similar transition from columnar to glassy microstructure increasing the carbon content is also observed for others $\mathrm{MeC} / \mathrm{a}-\mathrm{C}$ nanocomposites [52]. In the last micrograph (Fig. 9d), the typical features for power ratios above 2 are displayed. In this case, a broad columnar microstructure is observed oppositely to what is seen in coating R0.1. Such typical microstructure is most likely due to the lowering in amount and energy of the impinging species affecting the film growth [53]. This fact correlates with the dumping of the power applied to the WC target down to $150 \mathrm{~W}$ for R2 and R3 and, the subsequent decrease of the deposition rate displayed in Fig.1a.

In summary, after studying the chemical and phase composition by XPS, XRD, TEM/ED and Raman it can be concluded the following sequence. Initially, nanocrystalline hexagonal $\mathrm{W}_{2} \mathrm{C}$ ( $\gamma$-disordered type) phase is mainly formed by single sputtering of WC target. The incorporation of carbon leads to a progressive reduction of the crystalline domain size and the nucleation of the cubic $\beta-\mathrm{WC}_{1-\mathrm{x}}$ phase. From a total 
C content of 55 at.\% (R0.5) the formation of composite films containing nanocrystallites of cubic $\beta-\mathrm{WC}_{1-\mathrm{x}}$ phase dispersed in an amorphous carbon matrix is clearly manifested. Further increase of the $\mathrm{R}$ parameter leads to a progressive increment of the free amorphous carbon content becoming comparable to the crystalline fraction from R2.

\subsection{Thermal stability}

The thermal stability of the WC/a-C nanocomposite coatings was studied by annealing in vacuum $\left(10^{-1} \mathrm{mbar}\right)$ and the structural phase transformations were followed by in situ-XRD analysis. A detailed interpretation of the XRD and Raman analysis after annealing has been given previously [54]. Here, in Fig. 10a we display a sequence of the high-temperature XRD experiments for R1 sample to highlight the main conclusions. It can be seen that the sample does not change up to a temperature of 700 ${ }^{\circ} \mathrm{C}$ [55]. At this moment, the $\mathrm{WC}_{1-\mathrm{x}}$ phase transforms into $\mathrm{W}_{2} \mathrm{C}$ and $\mathrm{WC}$ phases that remain stable up to $900-1000{ }^{\circ} \mathrm{C}$ [56]. Afterwards, they begin to decompose originating metallic W. Fig. 10b shows the relative intensity of the different phases as a function of the temperature. The intensity of each peak is normalized by dividing its maximum intensity along the annealing to follow easily the critical temperatures for each transition. The critical temperature for the first transformation is observed to change from 400 to $800{ }^{\circ} \mathrm{C}$ when the carbon content increases from 33 at.\% (R0) to 64 at.\% (R1) [54]. The influence of the carbon content, controlled by the power ratios, is thus manifested in the thermal stability of the formed phases. The presence of an amorphous carbon matrix helps the stabilisation of the tungsten carbide phases and increases the oxidation resistance. This was further confirmed by thermal annealing up to $1100{ }^{\circ} \mathrm{C}$, 
when a higher concentration of carbide phases $\left(\mathrm{W}_{2} \mathrm{C}\right.$ and $\left.\mathrm{WC}\right)$ by decomposition of $\mathrm{WC}_{1-\mathrm{x}}$ is observed in the presence of free carbon. Besides, this carbon in excess can prevent the oxidation at high temperature of tungsten phases by partial removal forming CO species.

\subsection{Mechanical properties}

Table 2 provides the mechanical and tribological properties as a function of the total and amorphous free carbon contents. The maximum hardness is obtained for the R0 and R0.1 samples (36 and 40 GPa respectively) whilst the remaining samples exhibit average values between 16 to $25 \mathrm{GPa}$. Comparing with the literature, the values for the hardest samples are among the highest reported for W-C sputtered films. Investigations carried out by Quesnel et al. [4] found a maximum microhardness $(\mathrm{Hv}=26 \mathrm{GPa})$ at a carbon total concentration of about 40 at.\%. Likewise, Voevodin et al. [8] obtained a maximum hardness of $33 \mathrm{GPa}$ in WC/DLC nanocomposite coatings for 40 at.\% $\mathrm{C}$ and Palmquist et al. [36] $25 \mathrm{GPa}$ with 35 at.\% C. These carbon contents are similar to those measured for R0 and R0.1 samples in the range 33-37 at.\%.

According to the values of hardness $(\mathrm{H})$ and reduced Young modulus $\left(\mathrm{E}^{*}\right)$ as a function of a-C content (Fig. 11a), the samples can be classified into two groups: on one side, R0 and R0.1 (with high values of $\mathrm{H}$ and $\mathrm{E}^{*}$ and a-C contents below 10 at.\%) and on the other side, the remaining ones, whose mechanical properties are lower and decrease slightly with the increment of the a-C concentration from 10 to 31 at. $\%$. Attending to the chemical and microstructural characterization carried out in these samples, it seems that the enhancement of the hardness can be attributed to a highly dense microstructure formed by nanocrystals (below $10 \mathrm{~nm}$ ) of $\mathrm{W}_{2} \mathrm{C}(\mathrm{R} 0)$ and mixture of $\mathrm{W}_{2} \mathrm{C}$ and $\mathrm{WC}_{1-\mathrm{x}}(\mathrm{R} 0.1)$. This would be in agreement with the conclusion raised by 
Palmquist et al. who associated the maximum value of hardness at around 35 at. $\% \mathrm{C}$ for a mixture of $\mathrm{W}_{2} \mathrm{C}$ and $\mathrm{WC}_{1-\mathrm{x}}$ phases [36]. The second group, with 10-31 at.\% of a-C, can be defined as nanocomposite coatings comprising nanocrystalline $\mathrm{WC}_{1-\mathrm{x}}$ grains dispersed in an amorphous a-C matrix. The observed decrease in hardness results from the amorphisation of the WC phase (grain size below $3 \mathrm{~nm}$ ) and the increment of the soft a-C content. In particular, the enrichment in the latter limits the possibility of the nanocomposite strengthening effect to occur [17].

Elastic strain to failure $\left(\mathrm{H} / \mathrm{E}^{*}\right)$ and resistance to plastic deformation $\left(\mathrm{H}^{3} / \mathrm{E}^{* 2}\right)$ (resilience) have been commonly used to correlate them with the film toughness and wear behavior [16,57]. The experimental determination of toughness remains a challenging task in thin films due to their limited thickness and the influence of the substrate $[58,59]$. By considering the equation of the "critical strain energy release for fast fracture" $\left(G_{\mathrm{c}}=\pi a \sigma_{\mathrm{c}} / \mathrm{E}\right)$ [59], with $a$ as the length of a pre-existing crack, it is concluded that fracture toughness would be improved by both a low Young's modulus and a high critical stress for fracture $\left(\sigma_{\mathrm{c}}\right)$, which implies the need for a high hardness. Similarly, using the equation for fracture toughness $\left(K_{\mathrm{IC}}\right)$ measured by the crack length induced by indentation, the equation contains the ratio $\mathrm{E} / \mathrm{H}$ under the applied indentation load [59]. Therefore, in an attempt to correlate $\mathrm{H} / \mathrm{E}^{*}$ and $\mathrm{H}^{3} / \mathrm{E}^{* 2}$ with toughness and wear behavior, we have calculated them from the measured values of $\mathrm{H}$ and $\mathrm{E}^{*}$ for the coatings deposited under different conditions. In general, a low $\mathrm{E}^{*}$ becomes desirable, as it allows the given load to be distributed over a wider area. However, this argument (although valid) contradicts the conventional fracture mechanics theory, which predicts a high modulus to prevent crack growth [60]. The calculated $\mathrm{H} / \mathrm{E}^{*}$ and $\mathrm{H}^{3} / \mathrm{E}^{* 2}$ values are displayed in Table 2 and their dependence with the a-C contents are represented in Fig. 11b. Analogously to hardness, two groups are 
found: R0 and R0.1 (the nanocrystalline coatings) and the rest of them (the nanacomposites coatings). This is mainly consequence of the strong interplay between $\mathrm{H}$ and $\mathrm{E}^{*}$. Within the first group, it is observed that the R0 sample exhibits the maxima in the $\mathrm{H} / \mathrm{E}^{*}$ and $\mathrm{H}^{3} / \mathrm{E}^{* 2}$ parameters despite the hardest sample corresponds to $\mathrm{R} 0.1$. Galvan et al. [16] suggested that the total lack of columnar boundaries, as R0 does (cf. Fig. 9a), leads to further toughness enhancement and an improved resistance to plastic deformation. The samples from the second group show very similar values indicating a comparable behavior in terms of toughness and resilience. However, this conclusion can not be extended for the tribological properties as it will be discussed next.

\subsection{Tribological properties}

Friction coefficient $(\mu)$ and film wear rates $(\mathrm{k})$ are shown in Table 2 and their dependence with the a-C content is displayed in Fig. $12 \mathrm{a}$ and $12 \mathrm{~b}$, respectively. It should be mentioned that the $\mathrm{k}$ values for samples $\mathrm{R} 0$ and $\mathrm{R} 0.1$ are not provided, since the transfer of mating material (steel) to the surface makes impossible the estimation of the wear track. Friction coefficient exhibits a decrease from 0.8 to 0.2 by increasing the a-C content with a sudden change around 7 at. $\%$. The variation of the wear rate of the films along the series appears to correlate with the average friction coefficient. Similar behavior has been highlighted in other self-lubricant hard nanocomposites where the wear rate is not inversely proportional to the film hardness, as predicted by the Archard's law [61], but rather controlled by the properties of the lubricant phase $[11,62,63]$. The formation of a third body layer in the contact preserves the counterfaces from degradation and promotes an easy shear of the sliding surfaces as it has been demonstrated earlier in many DLC, $\mathrm{MoS}_{2}$ and carbon-based solid lubricants [64-68]. 
According to the film microstructure, crystalline and chemical composition presented in this work we can try to explain the observed tribological performance using the two categories described previously:

Group I (R0 and R0.1): The main characteristic of these coatings is the major presence of crystalline $\mathrm{W}_{2} \mathrm{C}$ and $\mathrm{WC}_{1-\mathrm{x}}$ phases with grain sizes ranging 5 to $10 \mathrm{~nm}$ with scarce a-C contents ( $\leq 7$ at.\%). They posses high hardness (36-40 GPa), maximum toughness and resilience but poor lubricant properties. They interact severely with the steel counterface producing wearing of the ball and iron transfer to the wear track.

Group II (R0.3 to R3): This class can be defined as nanocomposite coatings composed of a poor crystallized $\mathrm{WC}_{1-\mathrm{x}}$ phase surrounded by an amorphous carbon matrix. For the lowest a-C contents, where accordingly there is a higher concentration of the hard $\mathrm{WC}_{1-\mathrm{x}}$ phase, the production of abrasive debris particles contributes to accelerate the coating degradation achieving high frictions and high wear rates. When the a-C concentration is about 30 at.\% of the total carbon (R2 and R3), it can be seen how there is a drastic diminution of friction together with the wear rate. This fact can be explained by a change in the wear mechanism from mixed abrasive/lubricant to pure sliding controlled by the a-C phase generated in the contact. This was confirmed in our previous work by Raman analysis of the ball counterfaces after friction tests [63]. Under these conditions, the specific wear rates reach $\mathrm{k}$ values in the range of $10^{-8} \mathrm{~mm}^{3} / \mathrm{Nm}$, which are below typical wear rates of hard metal carbides and nitrides and comparable to that of metal doped or pure DLC coatings. Concerning friction, values as low as 0.2 for coatings with $\approx 30$ at. $\%$ of a-C are appropriated for operating in dry lubrication conditions similarly to many DLC and carbon-based compounds used in tribological applications [69]. 
If we compare now the values obtained for the ratios $H / E^{*}$ and $H^{3} / E^{* 2}$ with the wear rates, it is clear that the best results are not obtained from the hardest samples (i.e. the most resistant to plastic deformation). In fact, as previously highlighted, a significant improvement is obtained for the samples that contain sufficient lubricant phase to tune the wear mechanism from abrasive to lubricant. The samples prepared at lower ratios, R0 and R0.1, exhibit limited amount of a-C and their tribological performance is worse despite their enhanced hardness properties. These results differ from some previous publications, where the correlation between wear resistance and $\mathrm{H} / \mathrm{E}$ ratios was emphasized $[57,70]$. The tribological behavior is indeed controlled by the friction-induced phenomena at the contact and the prediction of the wear rate performance by estimation of the $\mathrm{H}^{3} / \mathrm{E}^{* 2}$ ratios appears to be inappropriate $[62,63]$.

\section{Conclusions}

Nanostructured WC/a-C coatings with variable contents of WC and amorphous carbon were prepared by controlling the sputtering power ratio applied to $\mathrm{WC}$ and graphite targets. The microstructural characterization by XRD and TEM/ED showed that increasing the $\mathrm{C}$ incorporation, the WC nanocrystalline phases evolve from $\gamma-\mathrm{W}_{2} \mathrm{C}$ to $\beta-\mathrm{WC}_{1-\mathrm{x}}$. Further $\mathrm{C}$ enrichment leads to the increment of the amorphous $\mathrm{C}$ content forming a nanocomposite structure of small $\mathrm{WC}_{1-\mathrm{x}}$ crystals dispersed in a-C matrix. The determination of the fraction of carbon atoms bonded to tungsten $\left(\mathrm{WC}_{\mathrm{x}}\right.$ phases $)$ or bonded to carbon (as a-C matrix phase) by XPS resulted crucial for understanding the mechanical and tribological behavior of the coatings. Thus, the transition point is found when the a-C content is situated around 10 at.\% (expressed in terms of total carbon content $\approx 50$ at. $\%$ ). This is also correlated with a microstructural transition point from nanocrystalline sub-stoichiometric WC compounds to nanocomposite $\mathrm{WC}_{1-\mathrm{x}} / \mathrm{a}-\mathrm{C}$ 
coatings. The nanocrystalline coatings are characterized by their high hardness (36-40 $\mathrm{GPa}$ ) and high friction (0.8). When the a-C becomes the dominant phase the friction can be reduced down to $\sim 0.2$ with excellent wear rate in the range of $10^{-8} \mathrm{~mm}^{3} / \mathrm{Nm}$ and moderate hardness (16-20 GPa). The friction mechanism appears thus controlled by the supply of disordered $\mathrm{sp}^{2}$-bonded carbon to the contact. When it is insufficient, the hard tungsten carbide debris particles are responsible of abrasive wear of the counterface and high friction conditions. Besides, the addition of the carbon phase provides higher thermal stability to the coatings preventing the degradation of the tungsten carbide phases by thermal decomposition and oxidation. In conclusion, it is demonstrated the advantageous of this simple sputtering route with separate targets for the hard and the soft lubricant phase to control the microstructure, chemical composition and therefore the tribo-mechanical properties for selected applications.

\section{Acknowledgments}

The authors are grateful to the Spanish Ministery of Science and Innovation (project $\mathrm{N}^{\mathrm{o}}$ MAT2007-66881-C02-01 and Consolider FUNCOAT CSD2008-00023), European Union (EXCELL project NMP3-CT-2005-515703) and I3 programme of CSIC for financial support. F. Hofer, B. Schaffer, W. Grogger from the Research Institute for Electron Microscopy, Graz (Austria) are acknowledged for collaborating in HRTEM analysis. 


\section{References}

[1] K.A. Taylor, Thin Solid Films 40 (1977) 201.

[2] B. Trindade, M.T. Vieira, E. Bauer-Grosse, Acta Mater. 46 (1998) 1731.

[3] Y. Pauleau, Ph. Gouy-Pailler, Matt. Letters 13 (1992) 157.

[4] E. Quesnel, Y Pauleau, P. Monge-Cadet, M. Brun, Surf. Coat. Technol. 62 (1993) 474.

[5] S. Neuville, A. Matthews, Thin Solid Films 515 (2007) 6619.

[6] K. Bewilogua, G. Bräuer, A. Dietz, J. Gäbler, G. Goch, B. Karpuschewski, B. Szyszka, Ann. CIRP 58 (2009) 608.

[7] C. Rebholz, J.M. Schneider, A. Leyland, A. Mathews, Surf. Coat. Technol. 112 (1999) 85.

[8] A.A. Voevodin, J.P.O`Neill, S.V. Prasad, J.S. Zabinski, J. Vac. Sci. Technol. A17 (1999) 986.

[9] A.A. Voevodin, J.P. O`Neill, J.S. Zabinski, Thin Solid Films 342 (1999) 194.

[10] A.A. Voevodin, J.S. Zabinski, Thin Solid Films 370 (2000) 223.

[11] A. Czyzniewski, Thin Solid Films 433 (2003) 180.

[12] A. Czyzniewski, W. Precht, J. Mat. Proc. Technol. 157-158 (2004) 274.

[13] M. Murakawa, T. Komori, S: Takeuchi, K. Miyoshi, Surf. Coat. Technol. 120-121 (1999) 646.

[14] R.A. Andrievski, Surf. Coat. Technol. 201 (2007) 6112.

[15] A.A. Voevodin, J.S. Zabinski. J. Mater. Sci. 33 (1998) 319.

[16] D. Galvan, Y.T. Pei, J.Th.M. De Hosson, Surf. Coat. Technol. 201 (2006) 590.

[17] R. Hauert, J. Pastcheider, Adv. Eng. Mater. 2 (2000) 247.

[18] S. Veprek, S. Reiprich, Thin Solid Films 265 (1995) 64.

[19] R. Hauert, Tribol. Int. 37 (2004) 991.

[20] C. Strondl, G.J. van der Kolk, T. Hurkmans, W. Fleischer, T. Trinh, N.M.

Carvalho, J.Th.M. De. Hosson, Surf. Coat. Technol. 142-144 (2001) 707.

[21] V. Derflinger, H. Brändle, H. Zimmermann, Surf. Coat. Technol. 113 (1999) 286. 
[22] S.J. Park, K.-R. Lee, D.-H. Ko, K.Y. Eun, Diamond Rel. Mater. 11 (2002) 1747.

[23] N. Radic, B. Grzeta, O. Milat, J. Ivkov, M. Stubicar, Thin Solid Films 320 (1998) 192.

[24] A.A. Voevodin, J.P. O’Neill, J.S. Zabinski, Surf. Coat. Technol. 116-119 (1999) 34.

[25] J.-H. Wu, M. Sanghavi, J.H. Sanders, A.A.Voevodin, J.S. Zabinski, D.A. Rigney, Wear 255 (2003) 859.

[26] K.K. Lai, H.H. Lamb, Chem. Mater. 7 (1995) 2284.

[27] C.M. Kelly, D. Garg, P.N. Dyer, Thin Solid Films 103 (1992)103.

[28] Y.-M. Sun, S.Y. Lee, A.M. Lemonds, E.R. Engbrecht, S. Veldman, J. Lozano, J.M. White, J.G. Ekert, I. Emesh, K. Pfeifer, Thin Solid Films 97 (2001) 109.

[29] B.Q. Yang, X.P. Wang, H.X. Zhang, Z.B. Wang, P.X. Feng, Matt. Letters 62 (2008) 1547.

[30] E. Eser, R.E. Ogilvie, K.A. Taylor, Thin Solid Films 67 (1980) 265.

[31] J.E. Krazanowski, J.L. Endrino, Matt. Letters 58 (2004) 3437.

[32] K. Abdelouahdi, C. Sant, C. Legrand-Buscema, P. Aubert, J. Perrière, G. Renou, Ph. Houdy, Surf. Coat. Technol. 200 (2006) 6469.

[33] G. Keller, I. Barzen, E. Erz, W. Dötter, S. Ulrich, K. Juang, H. Ehrhardt, Fresenius' Z. Anal. Chem. 341 (1991) 349.

[34] K. Fuchs, P. Rödhammer, E. Bertel, F.P. Netzer, E. Gornik, Thin Solid Films 151 (1987) 383.

[35] E.C. Weigert, M.P. Humbert, Z.J. Mellinger, Q.Ren, T.P. Beeber, Jr. L. Bao, J.G. Chen, J. Vac. Sci. Technol. A 26 (2008) 23.

[36] J.P. Palmquist. Z.S. Czigany, M. Oden, J. Neidhart, L. Hutman, U. Jansson, Thin Solid Films 444 (2003) 29.

[37] W.H. Kao, Surf. Coat. Technol. 201 (2007) 7392.

[38] A.S. Kurlov, A.I. Gusev, Inorganic Materials 42 (2006) 121.

[39] D.V. Suetin, I.R.Shein, A.L. Ivanovskii, J. Phys. Chem. Solids 70 (2009) 64.

[40] Y.D. Su, C.Q. Hu, C. Wang, M. Wen, W.T. Xheng, J. Vac. Sci. Technol. A 27 (2009) 167.

[41] http://www.phy.cuhk.edu.hk/ surface/XPSPEAK/ 
[42] W.C. Oliver, G.M. Pharr, J. Mater. Res. 7 (1992) 1564.

[43] P.E. Schmid, M.S. Sunaga, F. Lévy, J. Vac. Sci. Technol. A 16 (1998) 2870.

[44] R. Lamni, E. Martinez, S.G. Springer, R. Sanjinés, P.E. Schmid, F. Lévy, Thin Solid Films 447-448 (2004) 316.

[45] H. W. Hugosson, O. Eriksson, U. Jansson, B. Johansson, Phys. Rev. B 63 (2001) $134108-1$

[46] J. Pflüger, J. Fink, W. Weber, K. P. Bohnen, G. Crecelius, Phys. Rev. B 30 (1984) 1155.

[47] M.D. Abad, J.C. Sanchez-Lopez, N. Cusnir, R. Sanjines, J. Appl. Phys. 105 (2009) 033510 .

[48] A.C. Ferrari, J. Robertson, Phys. Rev. B 61 (2000) 14095.

[49] M.D. Demetriou, N.M. Ghoniem, A.S. Lavine, Acta Mater. 50 (2001) 1421.

[50] D.M. Mattox, G.J. Kominak, J. Vac. Sci. Technol. 9 (1972) 528.

[51] R.D. Bland, G.J. Kominiak, D.M. Mattox, J. Vac. Sci. Technol. 11 (1977) 671.

[52] Y.T. Pei, D. Galvan, J.Th.M. De Hosson, Acta Mater. 53 (2005) 4505.

[53] J.A. Thornton, Annu. Rev. Mater. Sci. 7 (1977) 239.

[54] S. El Mrabet, M.D. Abad, C. López-Cartes, D. Martínez-Martínez, J.C. SánchezLópez, Plasma Process Polym. 6 (2009) S444.

[55] R. Ospina, H.A. Castillo, V. Benavides, E. Restrepo, Y.C. Arango, D.F. Arias, A. Devia, Vacuum 81 (2006) 373.

[56] J. Luthin, Ch. Linsmeier, J Nucl. Mater. 290-293 (2001) 121.

[57] A. Leyland, A. Matthews, Wear 246 (2000) 1.

[58] S.J. Bull, J. Phys. D: Appl. Phys. 38 (2005) R393.

[59] S. Zhang, D. Sun, Y. Fu, H. Du, Surf. Coat. Technol. 198 (2005) 74.

[60] J. Musil, F. Kunc, H. Zeman, H. Poláková, Surf. Coat. Technol. 154 (2002) 304.

[61] J.F. Archard, J. Appl. Phys. 24 (1953) 981.

[62] D. Martínez-Martínez, C. López-Cartes, A. Fernández, J.C. Sánchez-López, Surf. Coat. Technol. 203 (2008) 756. 
[63] J.C. Sánchez-López, D. Martínez-Martínez, M.D. Abad, A. Fernández, Surf. Coat. Technol. 204 (2009) 947.

[64] R. Memming, H.J. Tolle, P.E. Wierenga, Thin Solid Films 143 (1986) 31.

[65] Y. Liu, A. Erdemir, E.I. Meletis, Surf. Coat. Technol. 86-87 (1996) 564.

[66] I.L. Singer, Langmuir 12 (1996) 4486.

[67] J.C. Sánchez-López, A. Erdemir, C. Donnet, T.C. Rojas, Surf. Coat. Technol. 163$164,444-450$ (2003).

[68] T.W. Scharf, I.L. Singer, Tribol. Lett. 36 (2009) 43.

[69] J.C. Sánchez-López, A. Fernández, Doping and Alloying Effects on DLC coatings, in: A. Erdemir, C. Donnet (Eds.), Tribology of Diamond-Like Carbon Films: Fundamentals and Applications, Springer, New York, 2008, pp. 311-338.

[70] Y.T. Pei, D. Galvan, J.Th.M. De Hosson, C. Strondl, J. Eur. Ceram. Soc. 26 (2006) 565 . 


\section{Figure captions}

Fig. 1. (a) Deposition rate of coatings and (b) atomic percentages of W, C and $\mathrm{O}$ estimated by XPS as a function of power ratio.

Fig. 2. (a) XPS spectra of the C 1s and (b) W $4 \mathrm{f}$ photoelectron peaks for the studied coatings.

Fig. 3. (a) A representative example of the XPS fitting of the C $1 \mathrm{~s}$ and (b) W $4 \mathrm{f}$ spectra for the coating $\mathrm{R} 1$ before and after $\mathrm{Ar}^{+}$bombardment.

Fig. 4. Fraction of $\mathrm{C}$ bonded to $\mathrm{W}\left(\mathrm{C}_{\mathrm{C}-\mathrm{W}} / \mathrm{W}_{\mathrm{W}-\mathrm{C}}\right)$ (stoichiometry of $\mathrm{WC}_{\mathrm{x}}$ phases) and fraction of total $\mathrm{C}$ total with respect to $\mathrm{W}$ in the tungsten carbide $\left(\mathrm{C}_{\text {total }} / \mathrm{W}_{\mathrm{W}-\mathrm{C}}\right)$ (stoichiometry of WC/C nanocomposite).

Fig. 5. (a) Raman spectra of the WC/a-C nanocomposite films as-deposited. (b) GPosition and $\mathrm{I}_{\mathrm{D}} / \mathrm{I}_{\mathrm{G}}$ parameter versus power ratio

Fig. 6. (a) Diffractograms for the WC/a-C films as a function of R. (b) Detail in the region $30-50^{\circ}$. The inset shows the absence of diffraction peaks in the low angle region for R0 film. The lines and symbols indicate the positions of the diffraction peaks for $\mathrm{WC}_{1-\mathrm{x}}$ and $\mathrm{W}_{2} \mathrm{C}$ patterns (JCPDS cards numbers: 20-1316 and 35-0776, respectively)

Fig. 7. TEM planar view of samples (a) R0, (b) R0.1, (c) R0.5 and (d) R3 and their corresponding electron diffraction patterns.

Fig. 8. (a) HRTEM micrographs of R0.1 with ED diagram associated indexed with the different orientations and possible phases. Interplanar spacings shown for different nanocrystals. (b) "Zero-Loss" HR TEM for R1 and ED diagram associated. Crystal is remarked on the micrograph.

Fig. 9. Cross-section SEM micrograph of WC/a-C nanocomposites as representatives (a) R0, (b) R0.1, (c) R1 and (d) R2 coatings. 
Fig. 10. (a) High-temperature XRD and (b) relative intensity of the different crystalline phases as a function of the temperature for the coating $\mathrm{R} 1$. The $\mathrm{WC}_{1-\mathrm{x}}, \mathrm{W}_{2} \mathrm{C}, \mathrm{WC}$ and $\mathrm{W}$ patterns correspond to the JCPDS cards numbers: 20-1316, 35-0776, 72-0097 and 011203 respectively)

Fig. 11. (a) Correlation between different mechanical properties: hardness $(H)$ and reduced Young's modulus $\left(\mathrm{E}^{*}\right)$; (b) Elastic strain to failure $\left(\mathrm{H} / \mathrm{E}^{*}\right)$ and resistance to plastic deformation $\left(\mathrm{H}^{3} / \mathrm{E}^{* 2}\right)$, as a function of a-C content.

Fig. 12. (a) Tribological properties: friction coefficient and (b) wear rate as a function of the a-C content. 


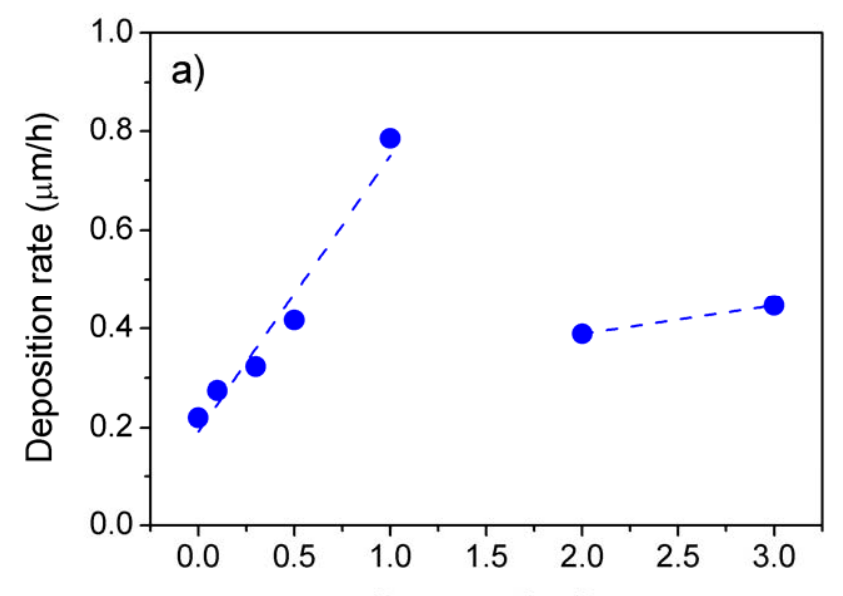

Power ratio, $R$ 


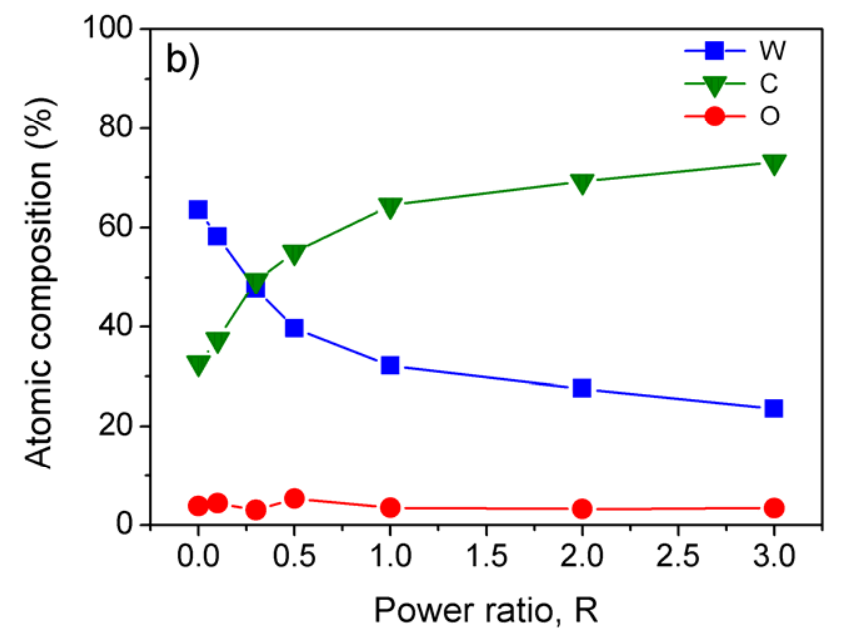


a)

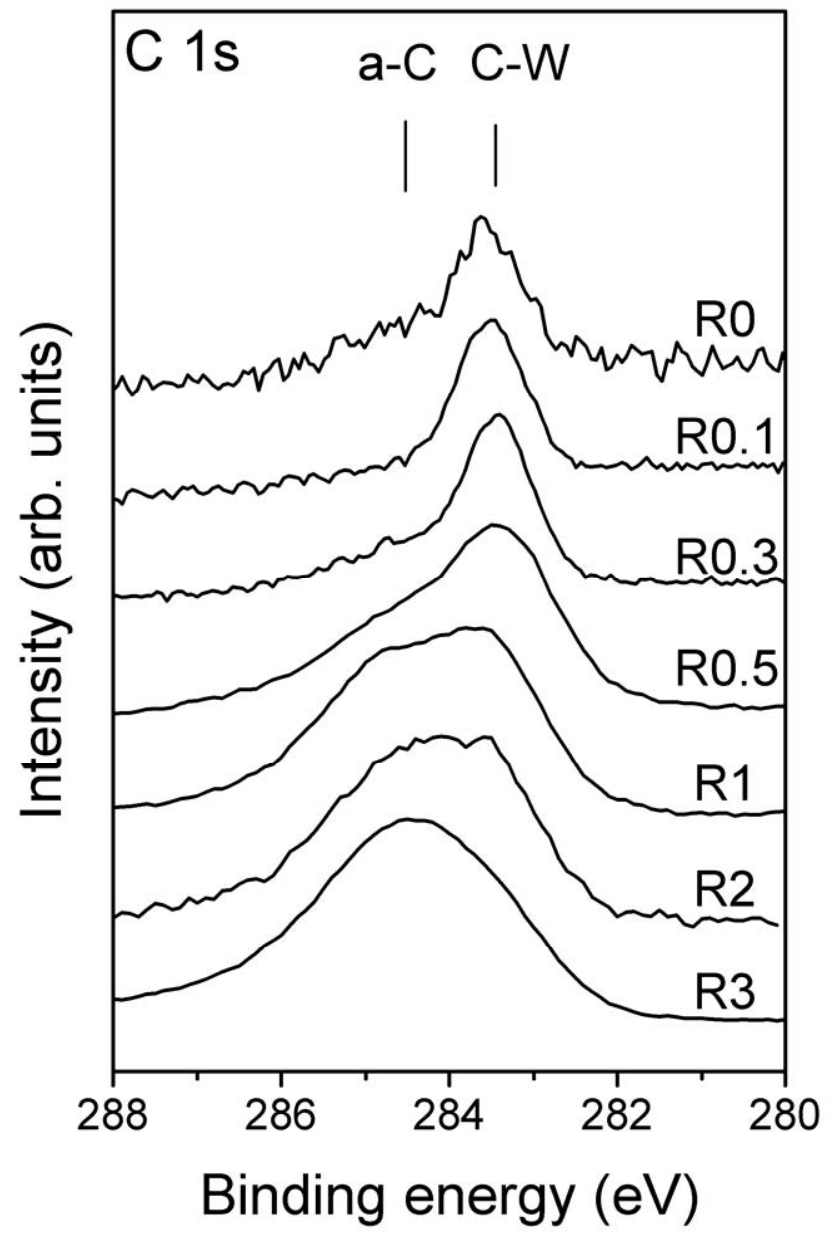


b)

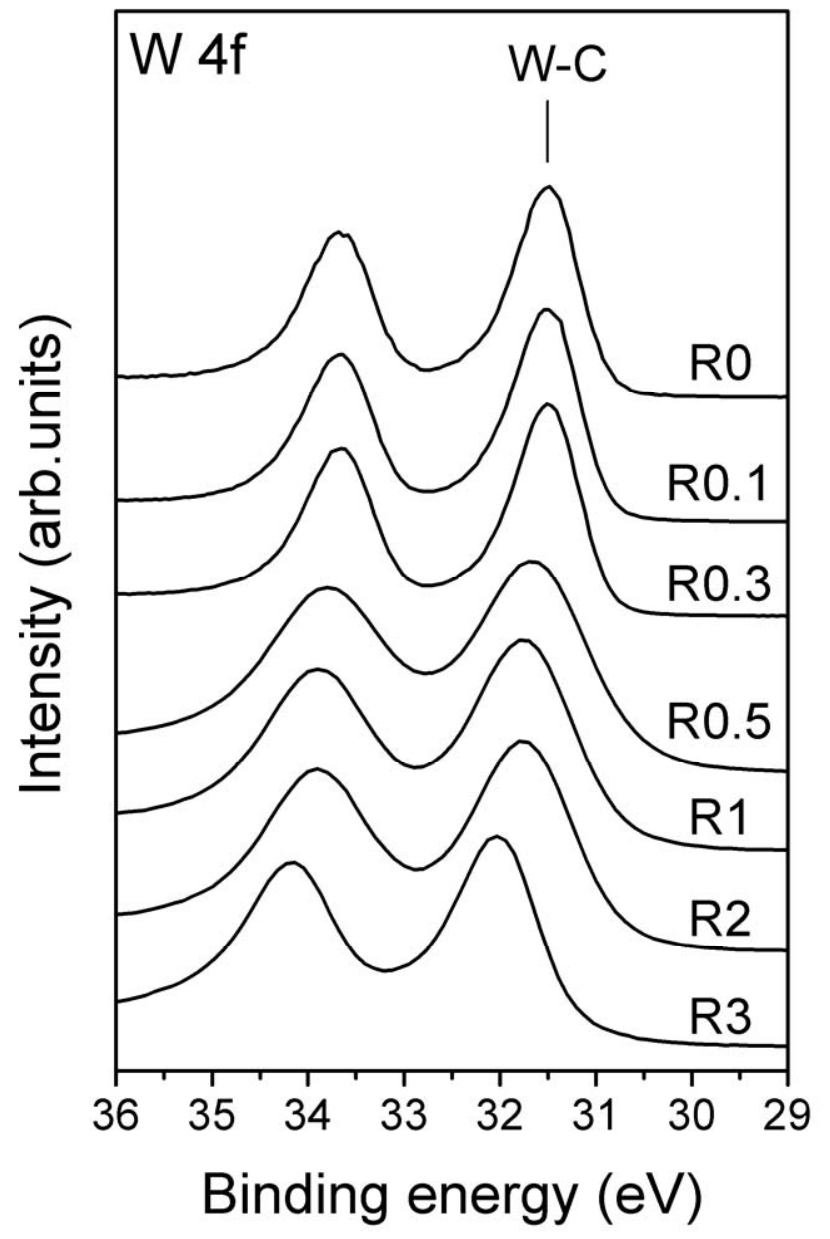




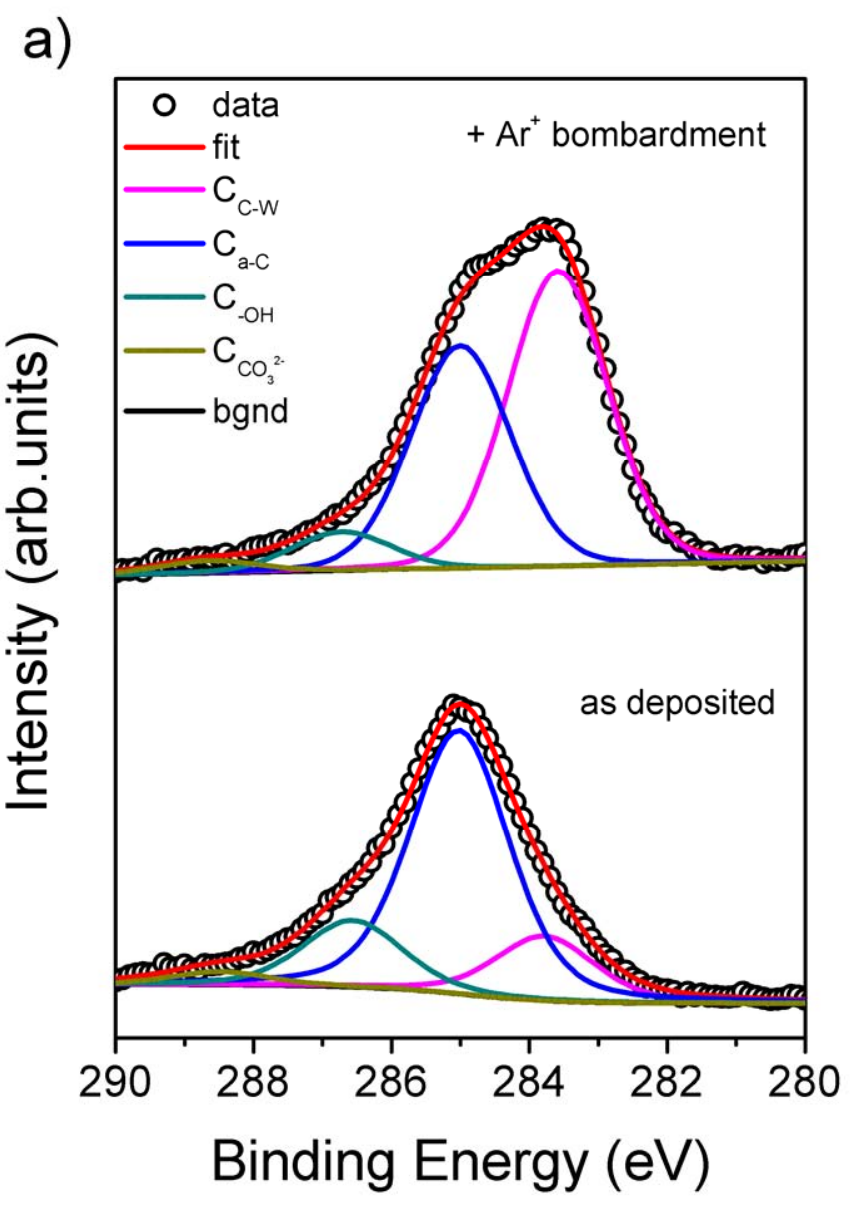




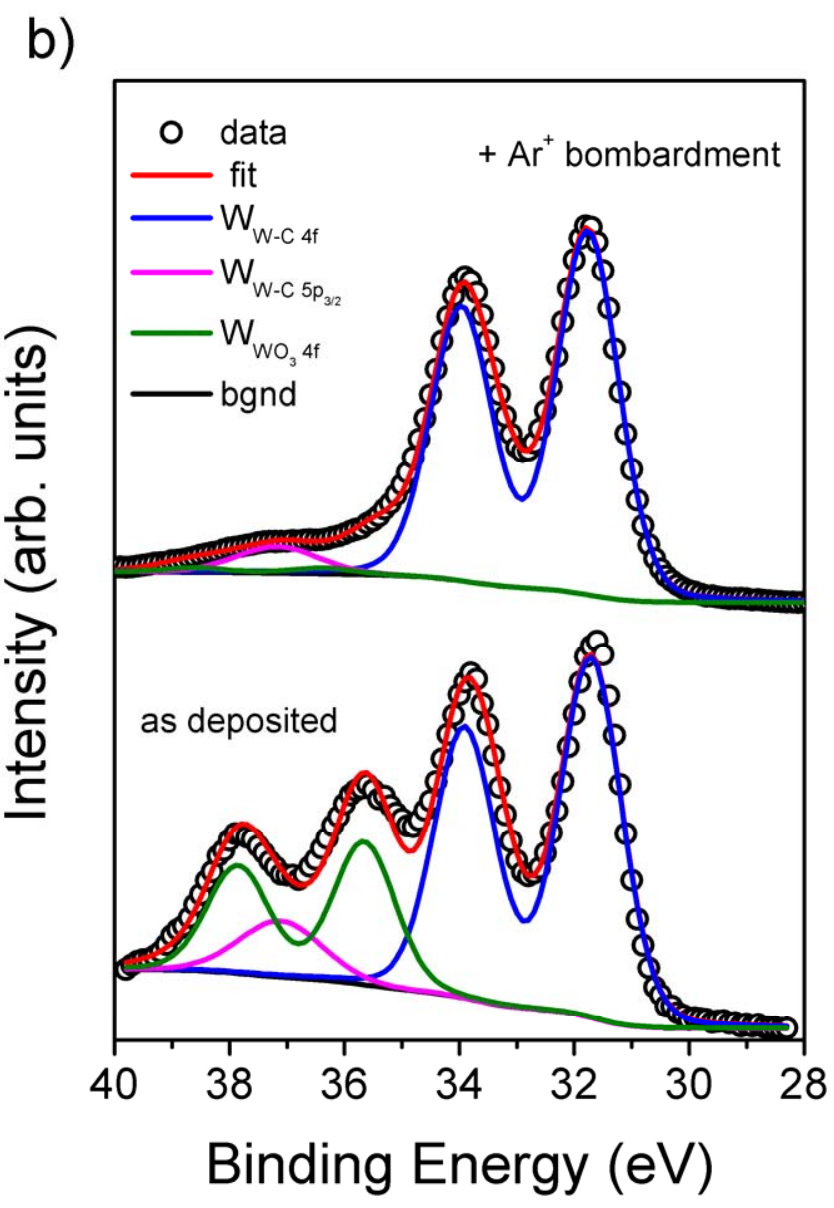




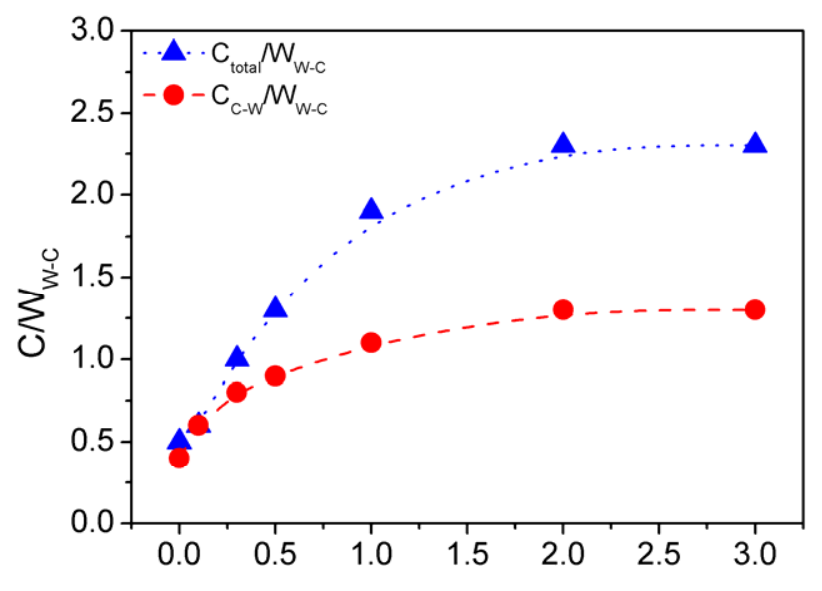

Power ratio, $R$ 


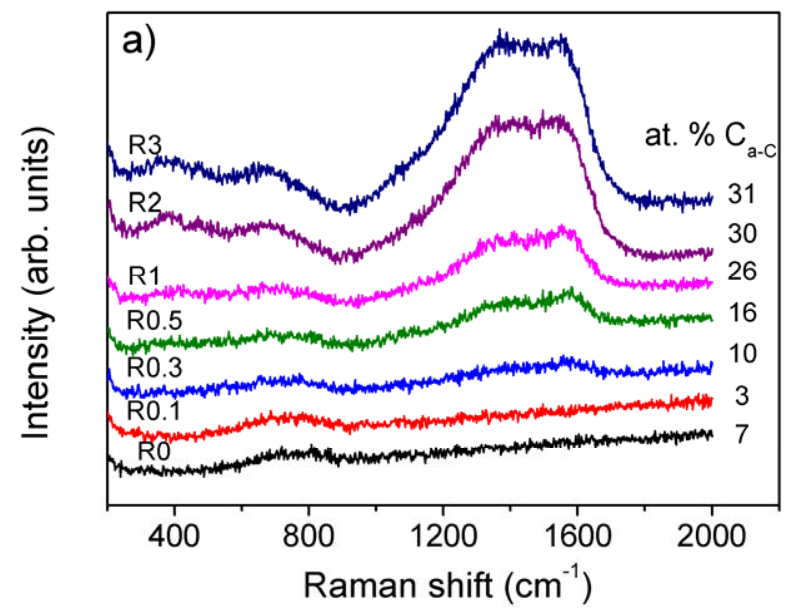




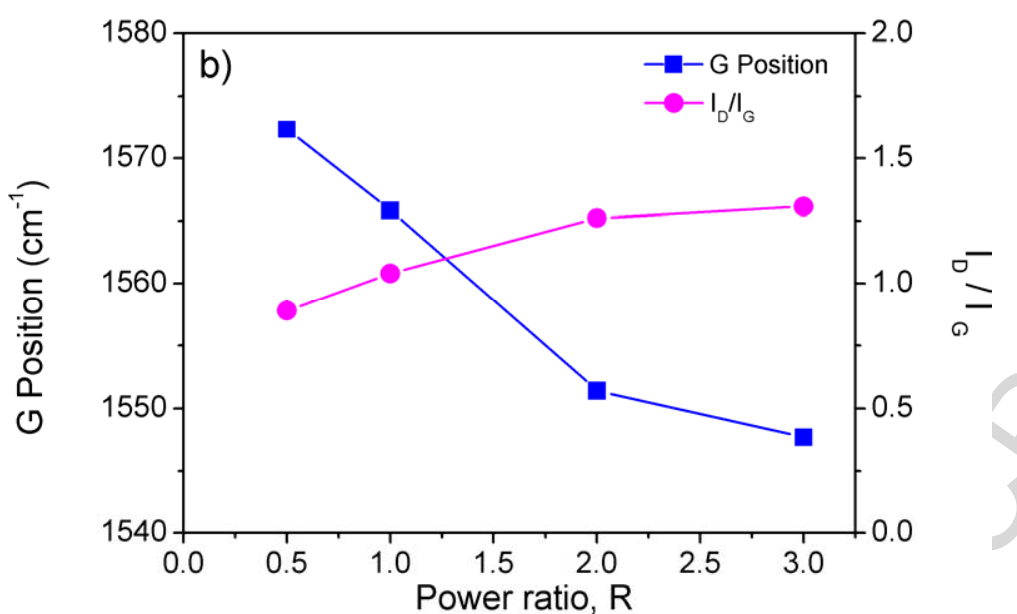




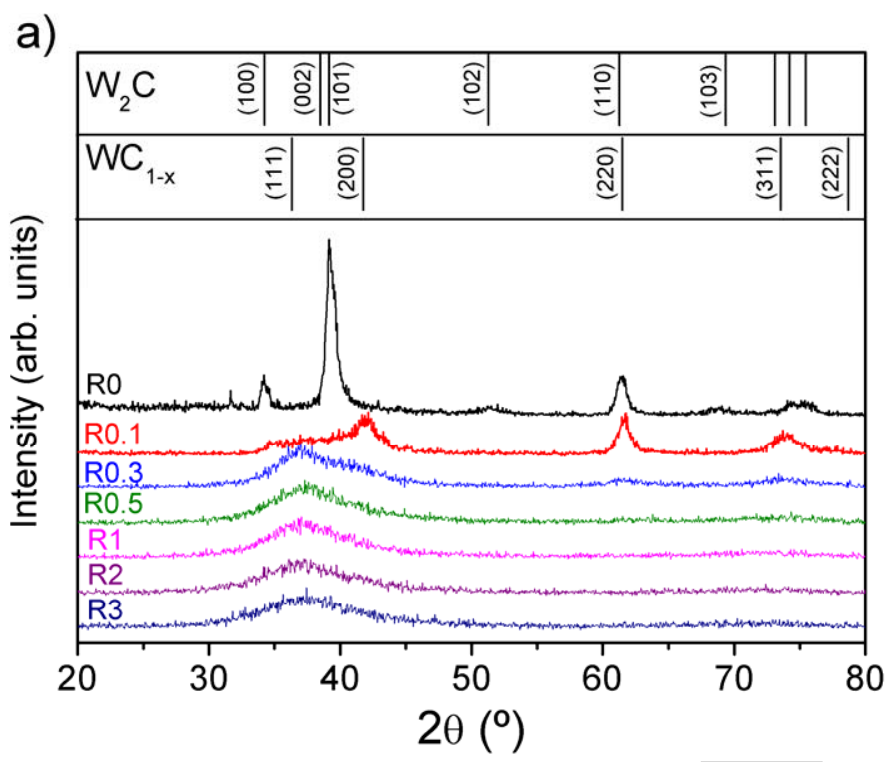


b)

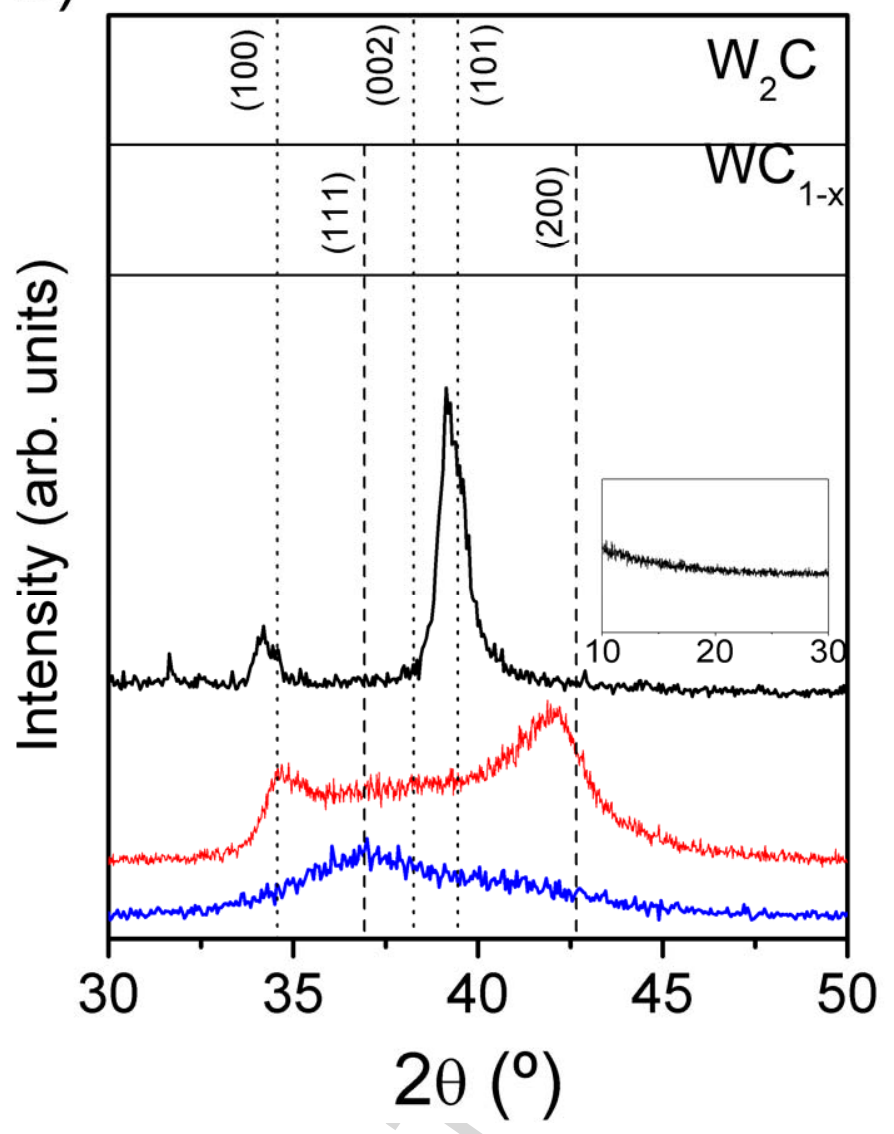




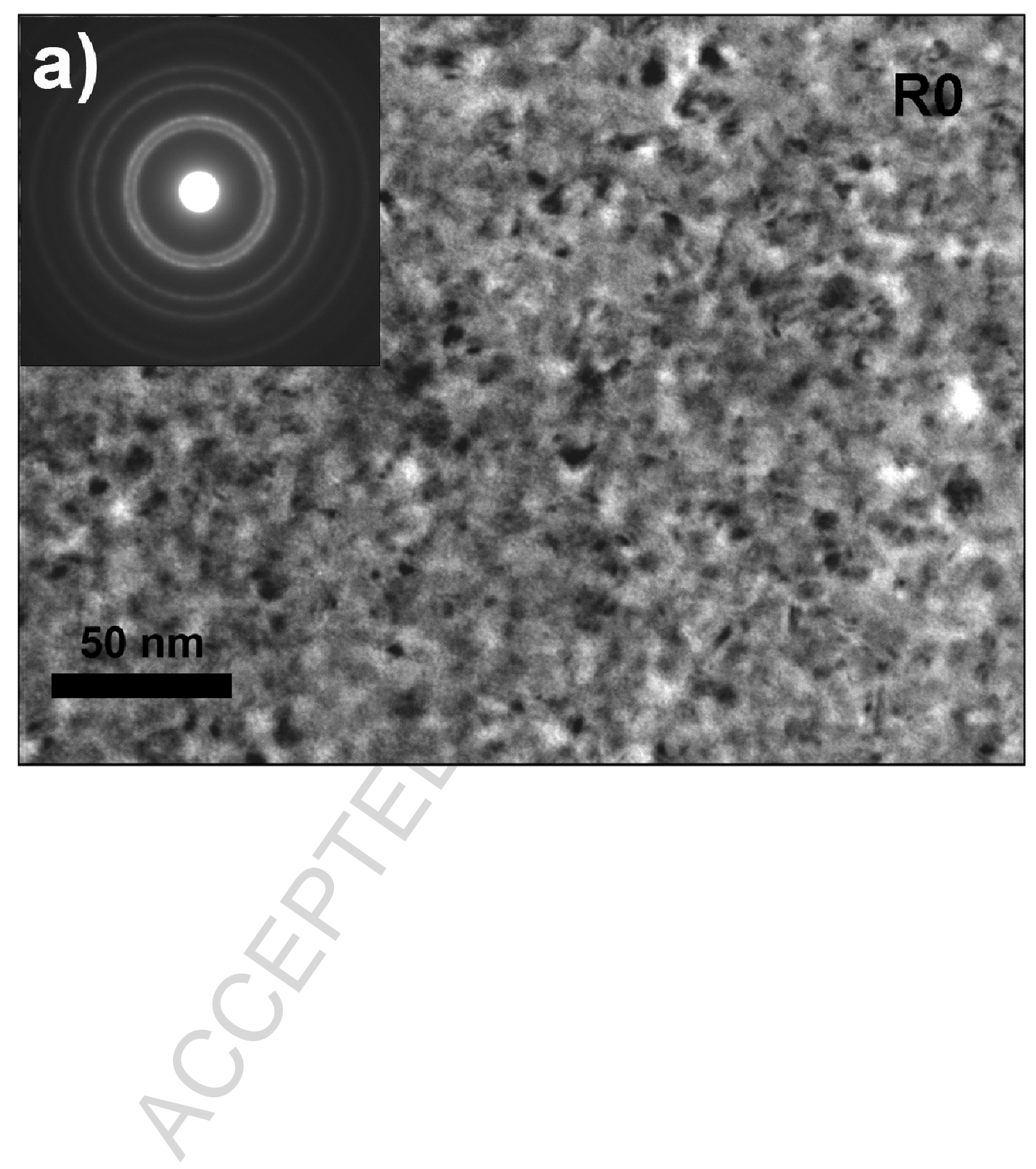




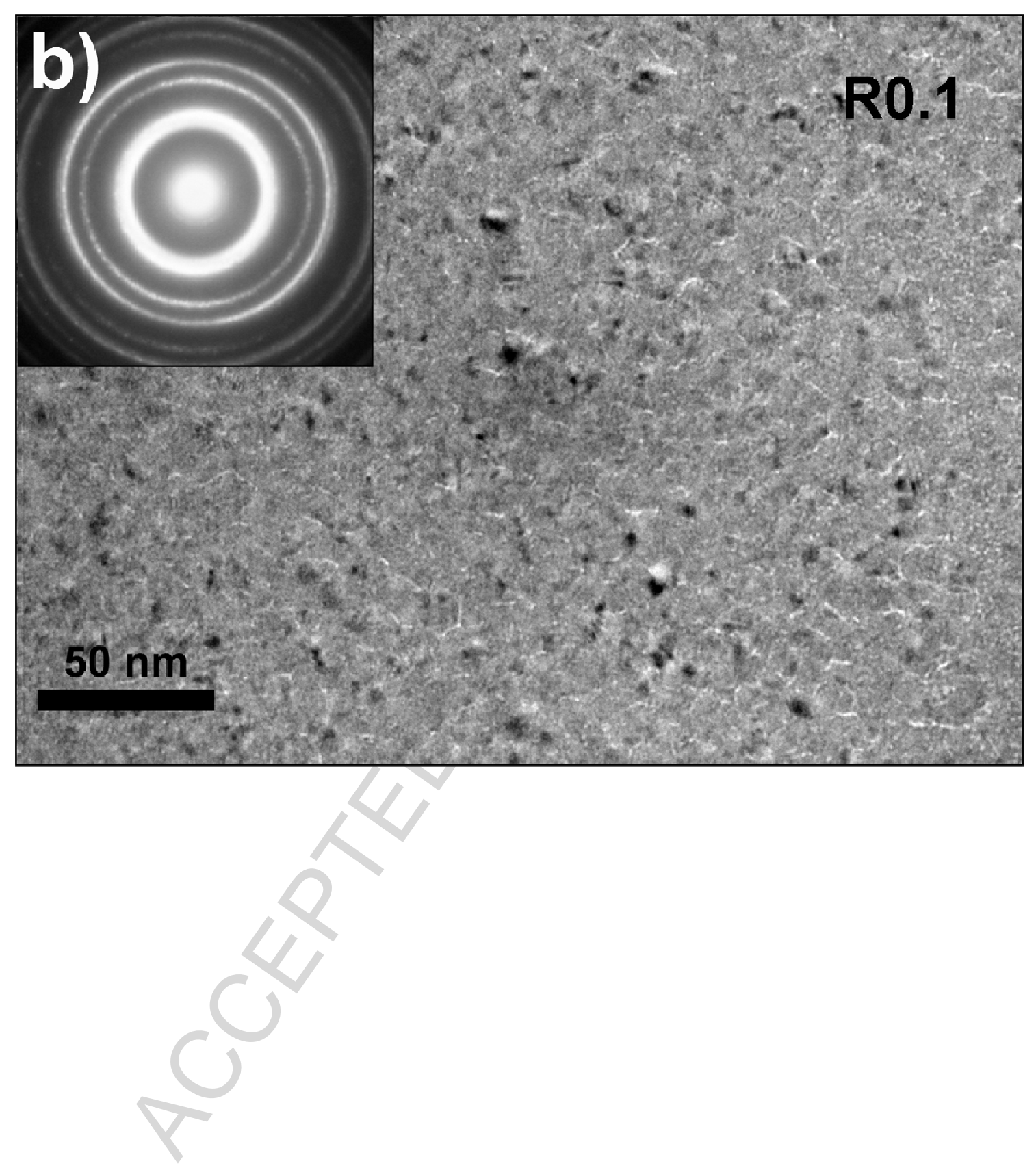




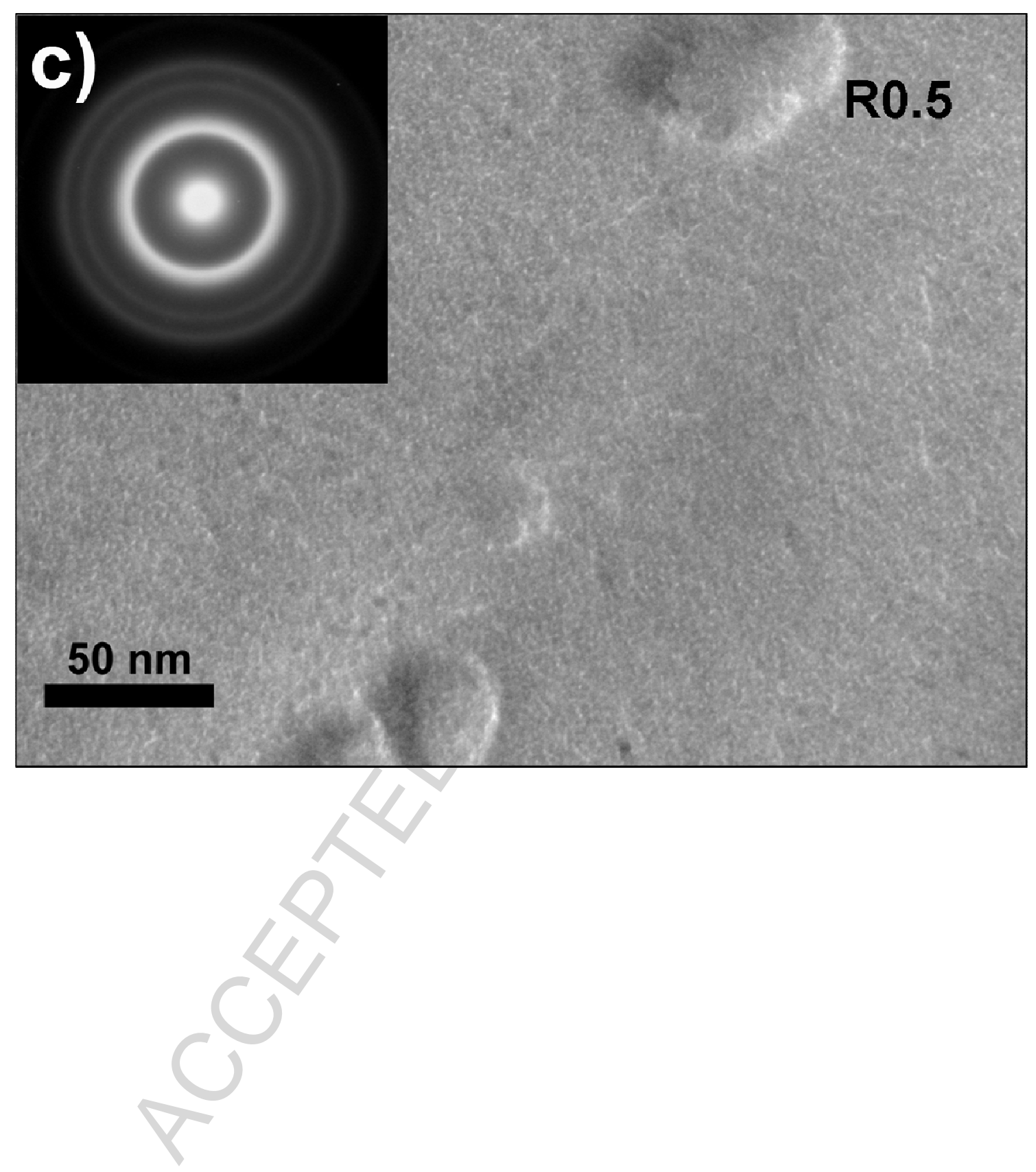




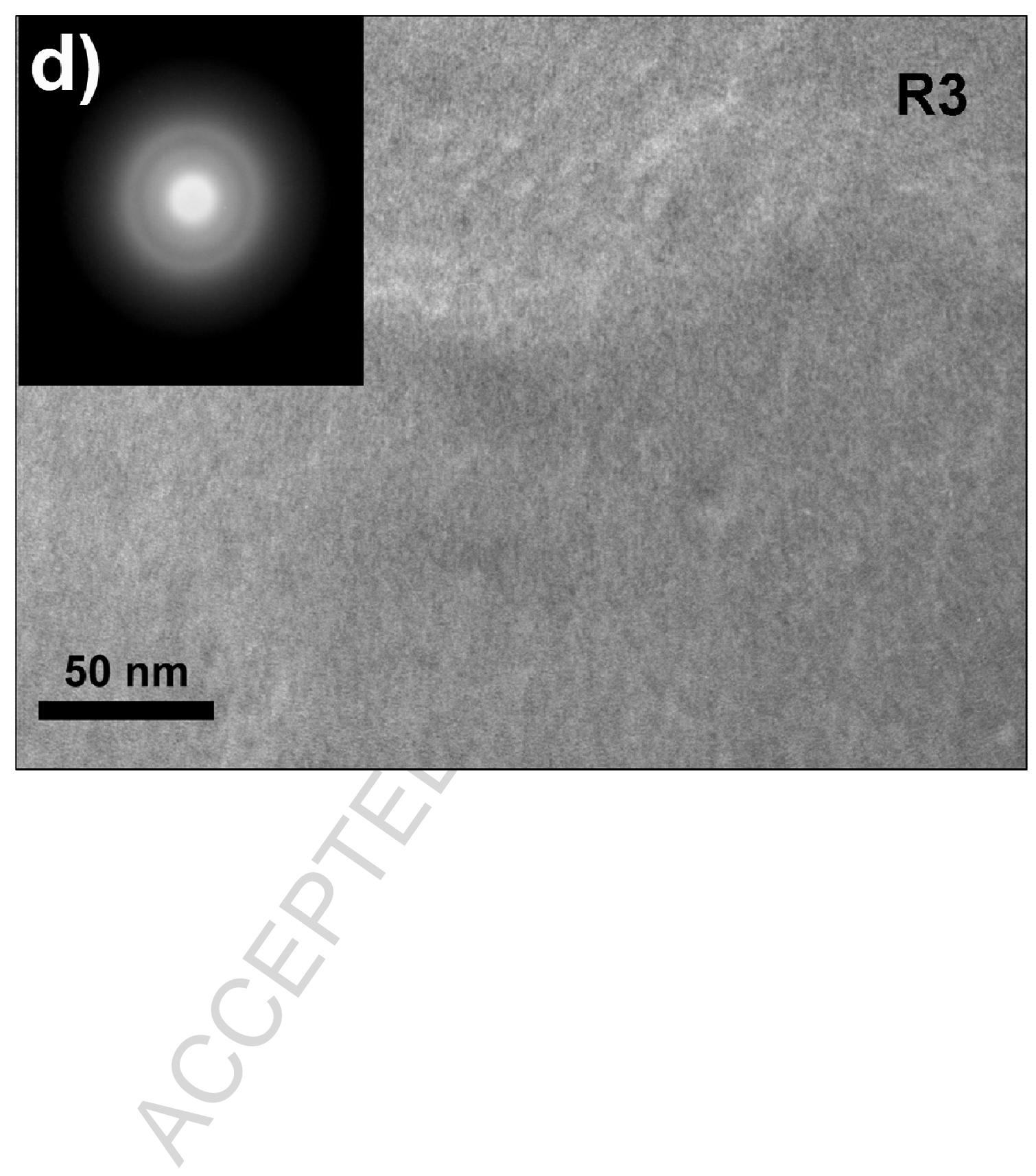




\section{ACCEPTED MANUSCRIPT}

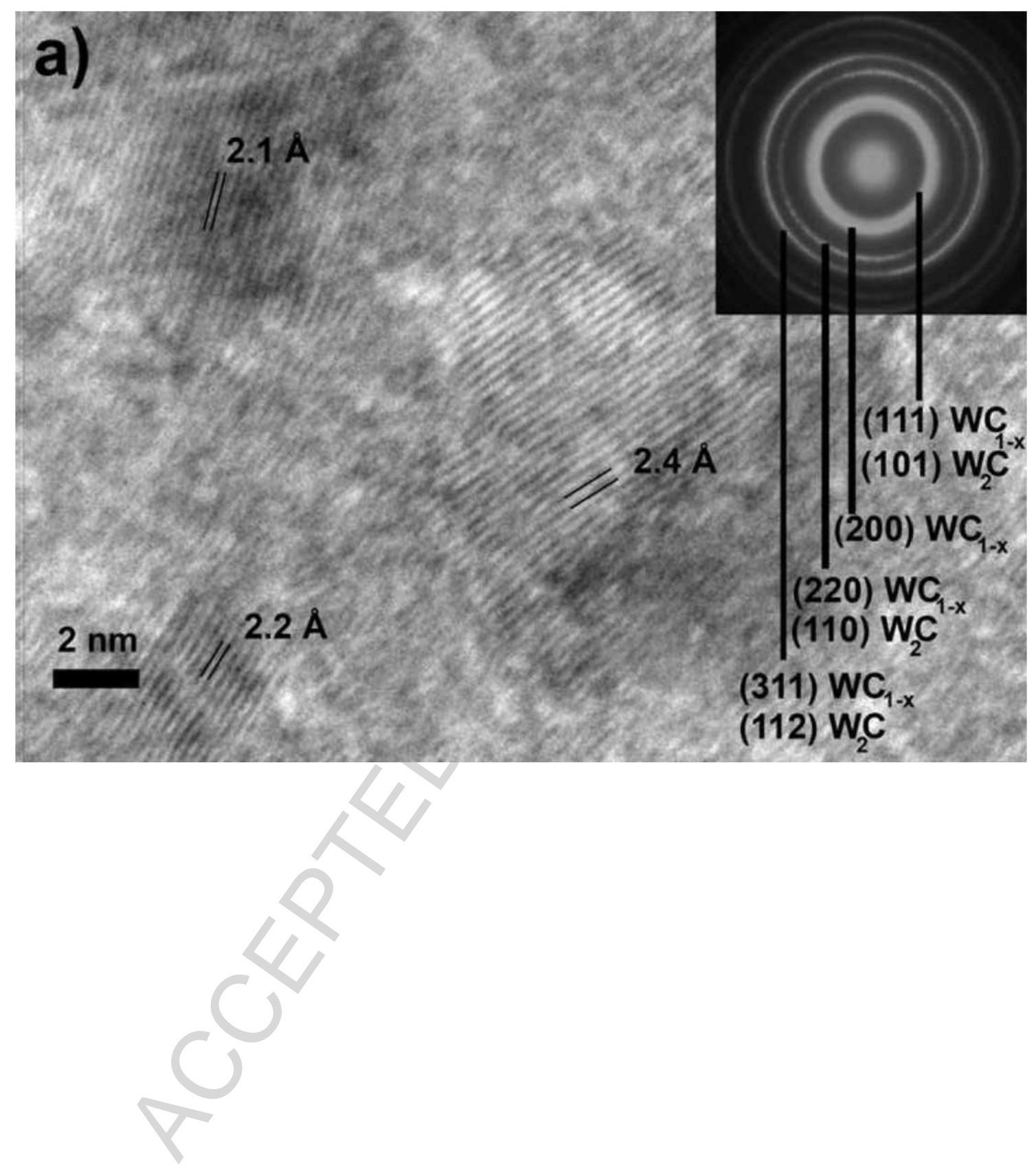




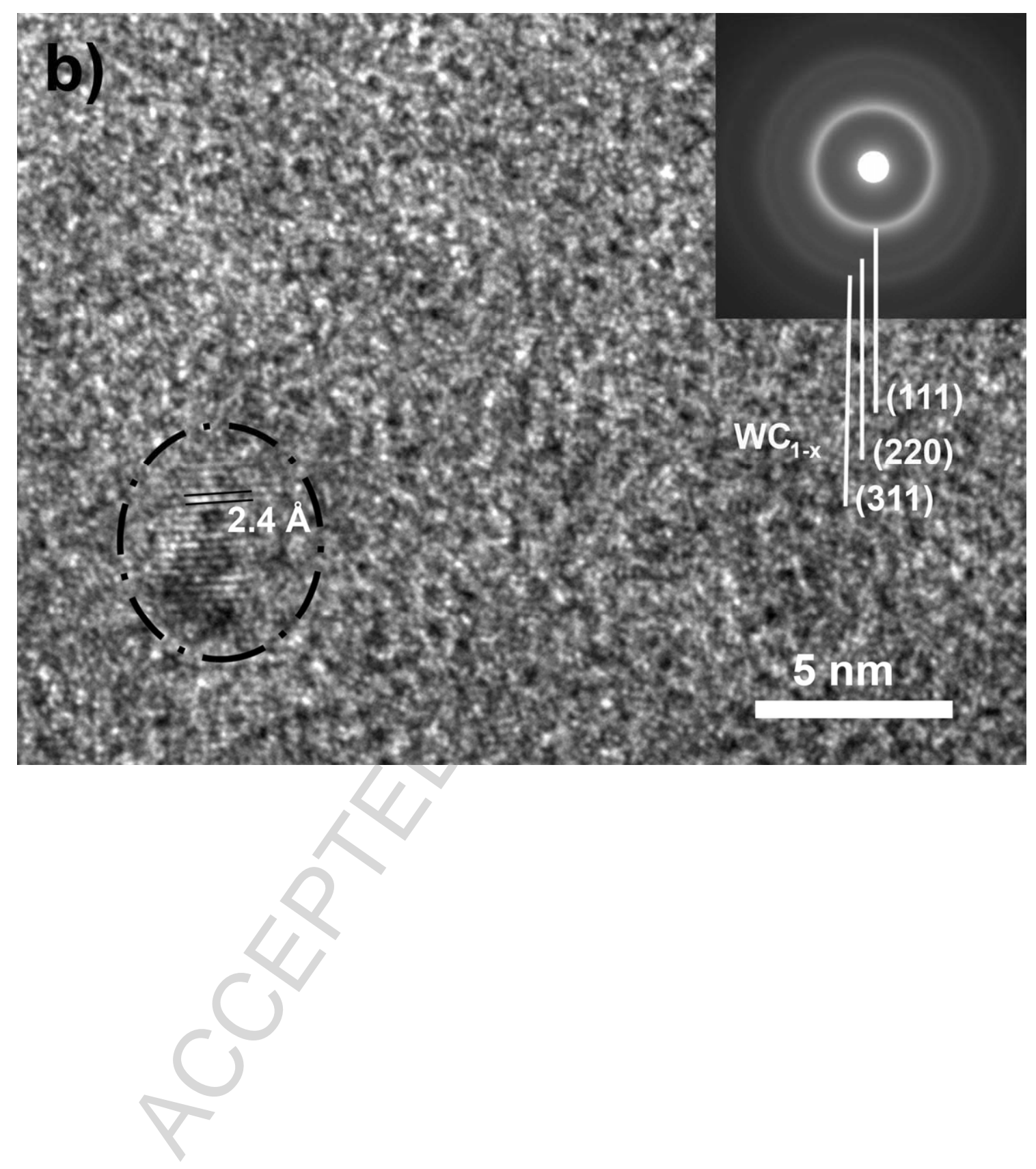




\section{a)}

\section{$500 \mathrm{~nm}$}




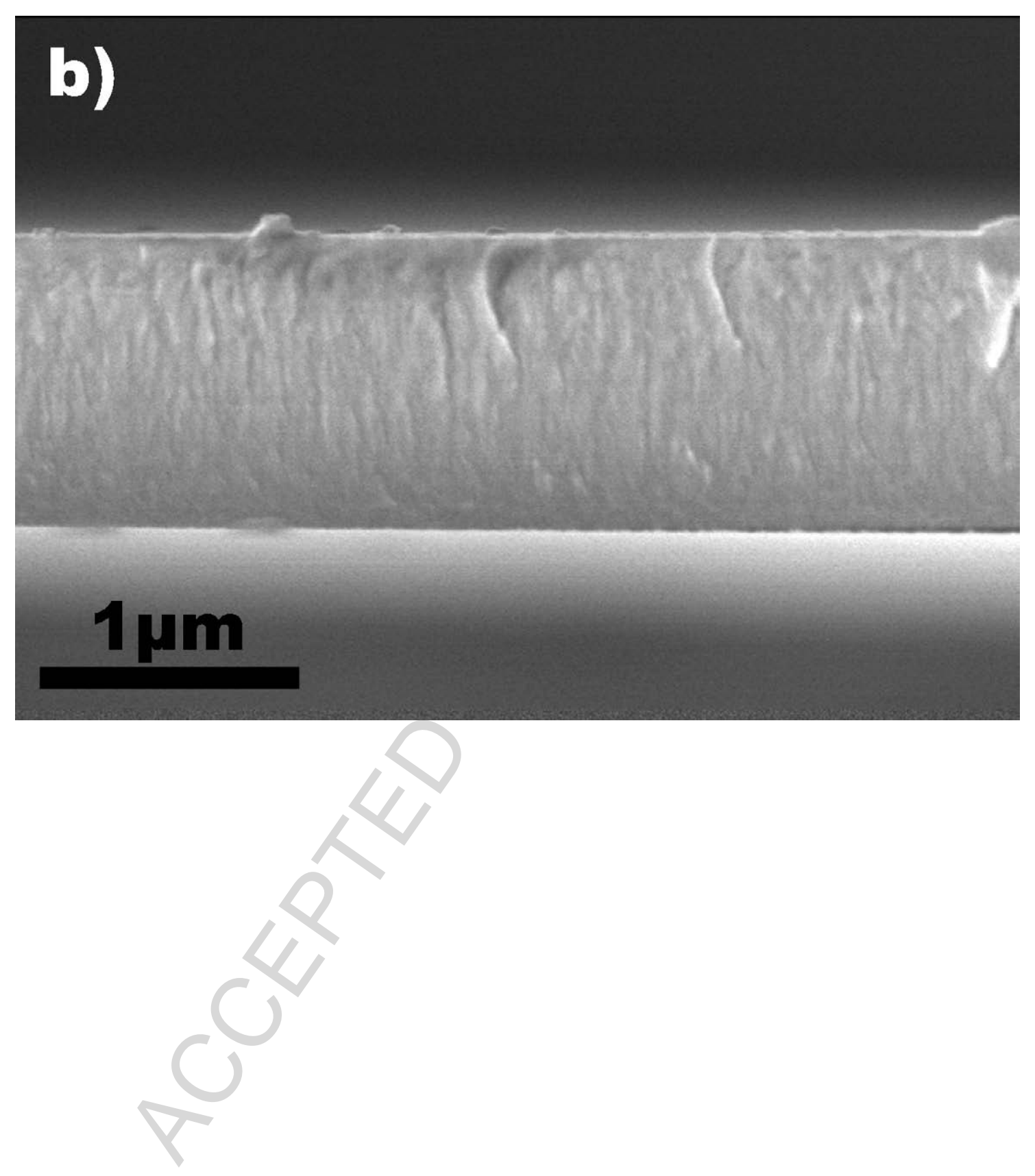




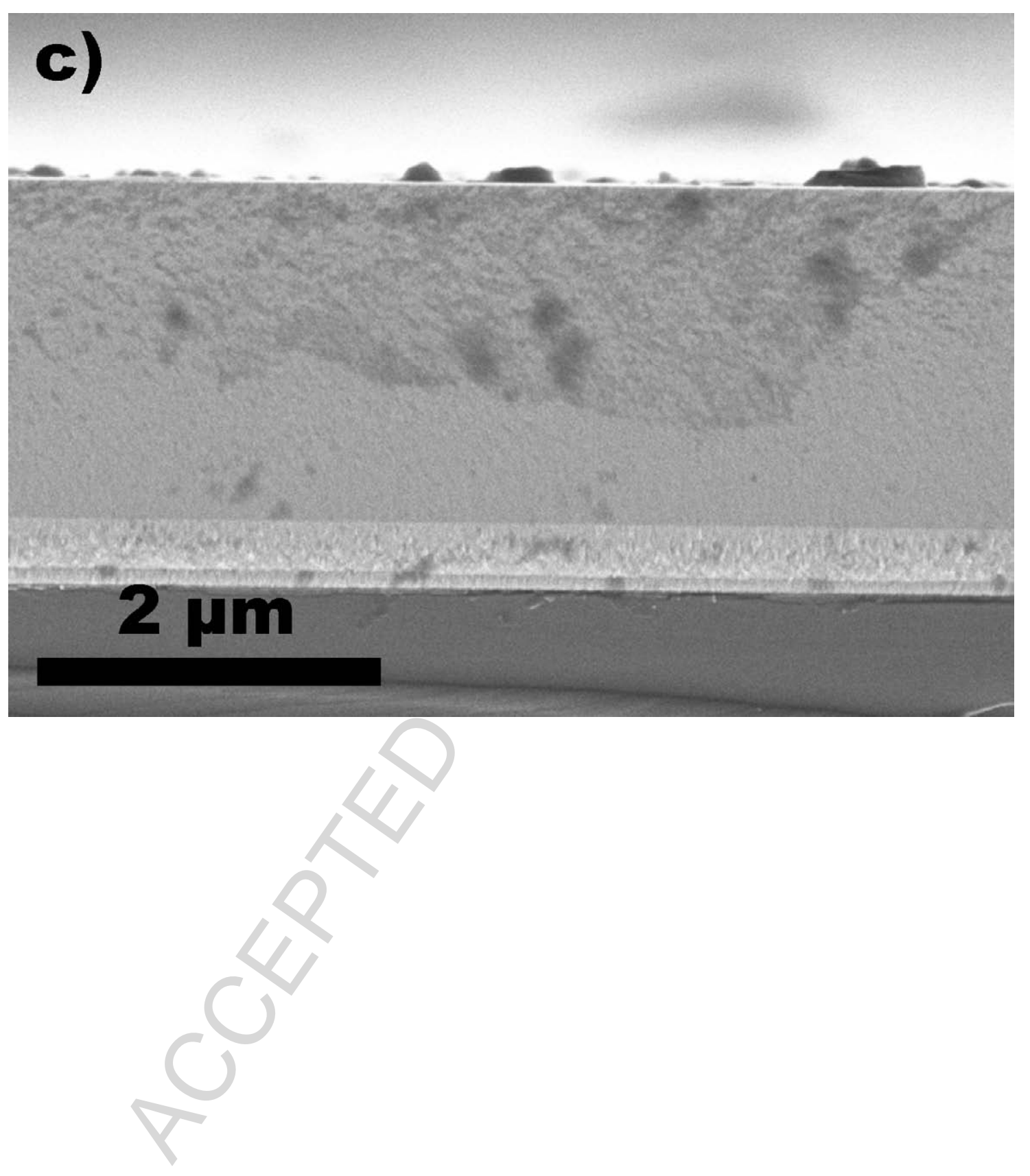




\section{ACCEPTED MANUSCRIPT}

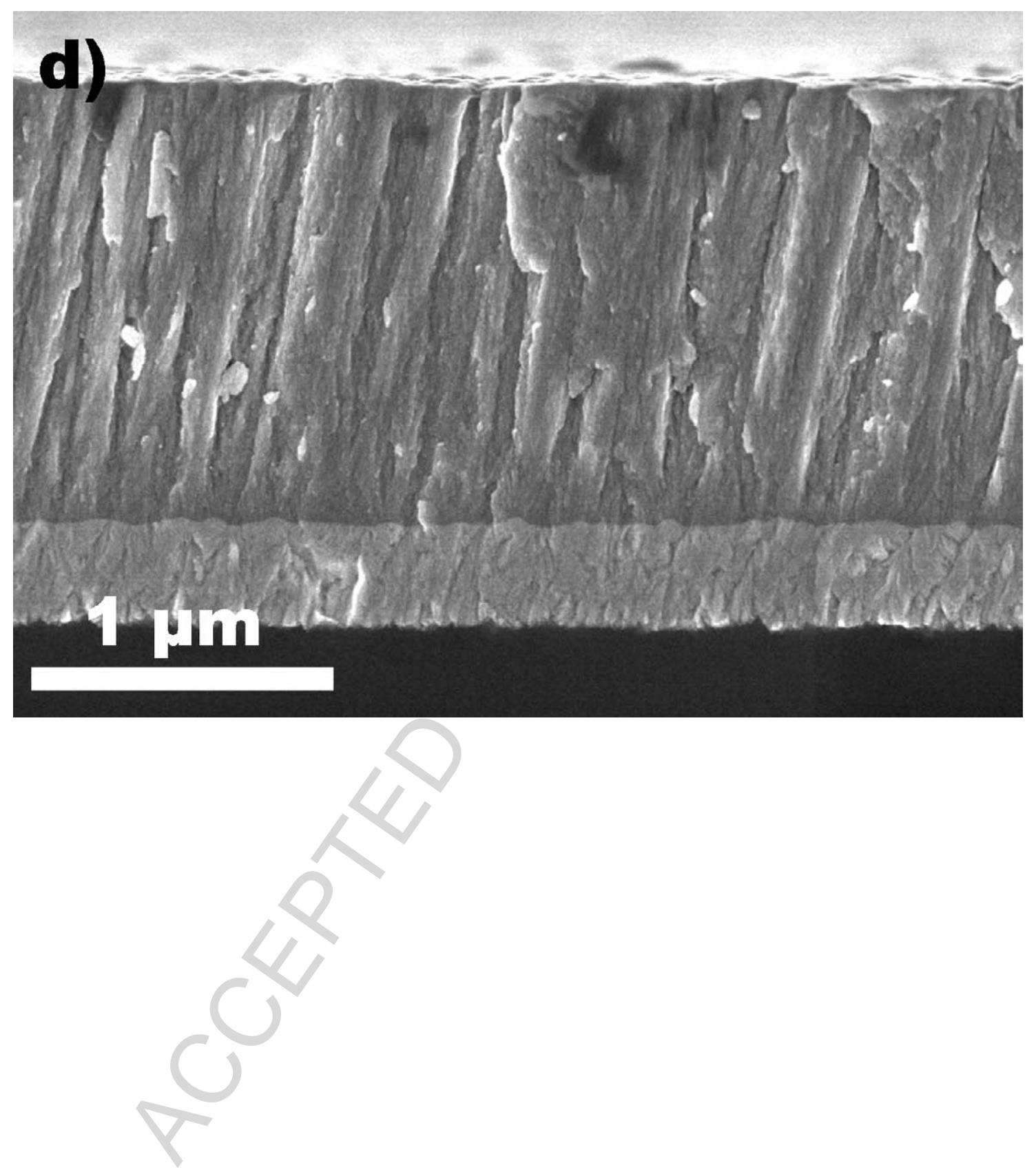


a)

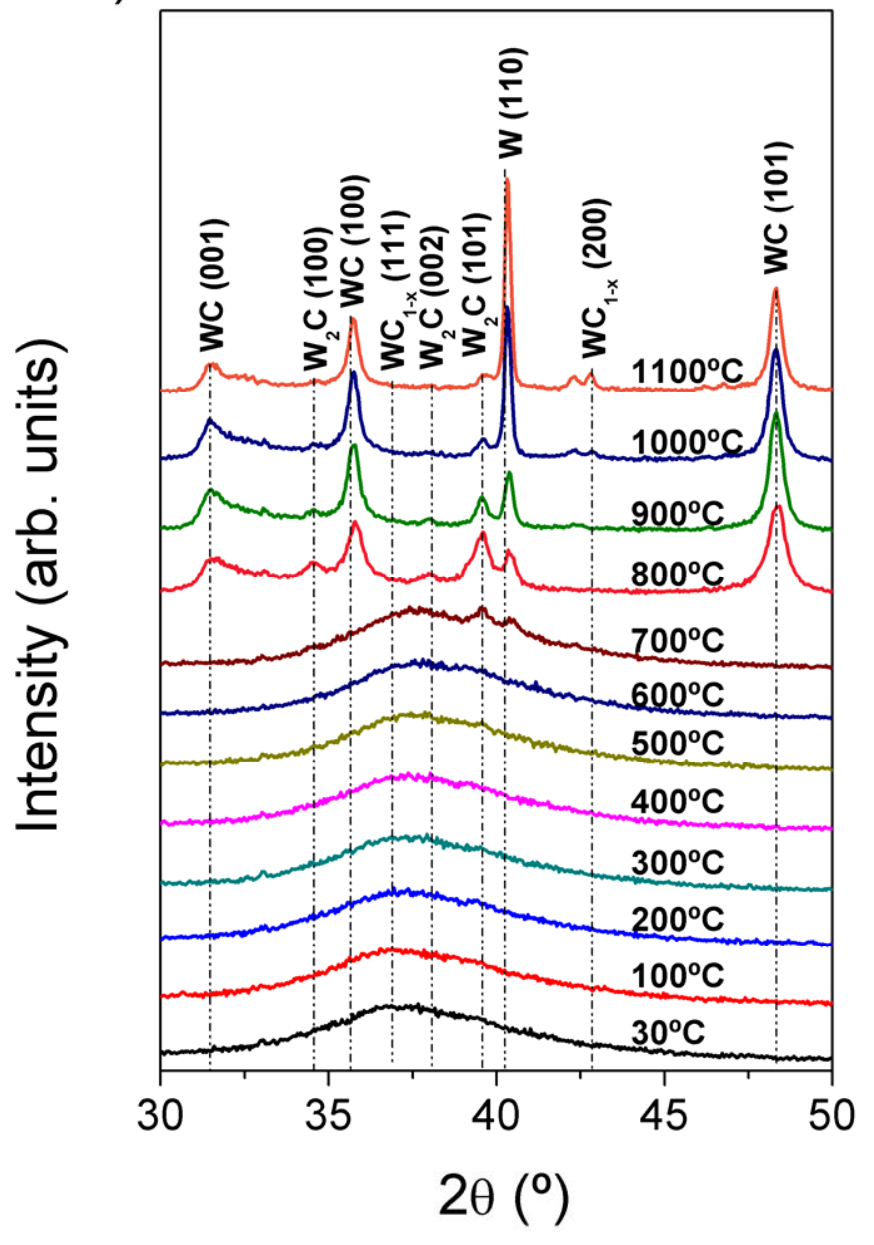


b)

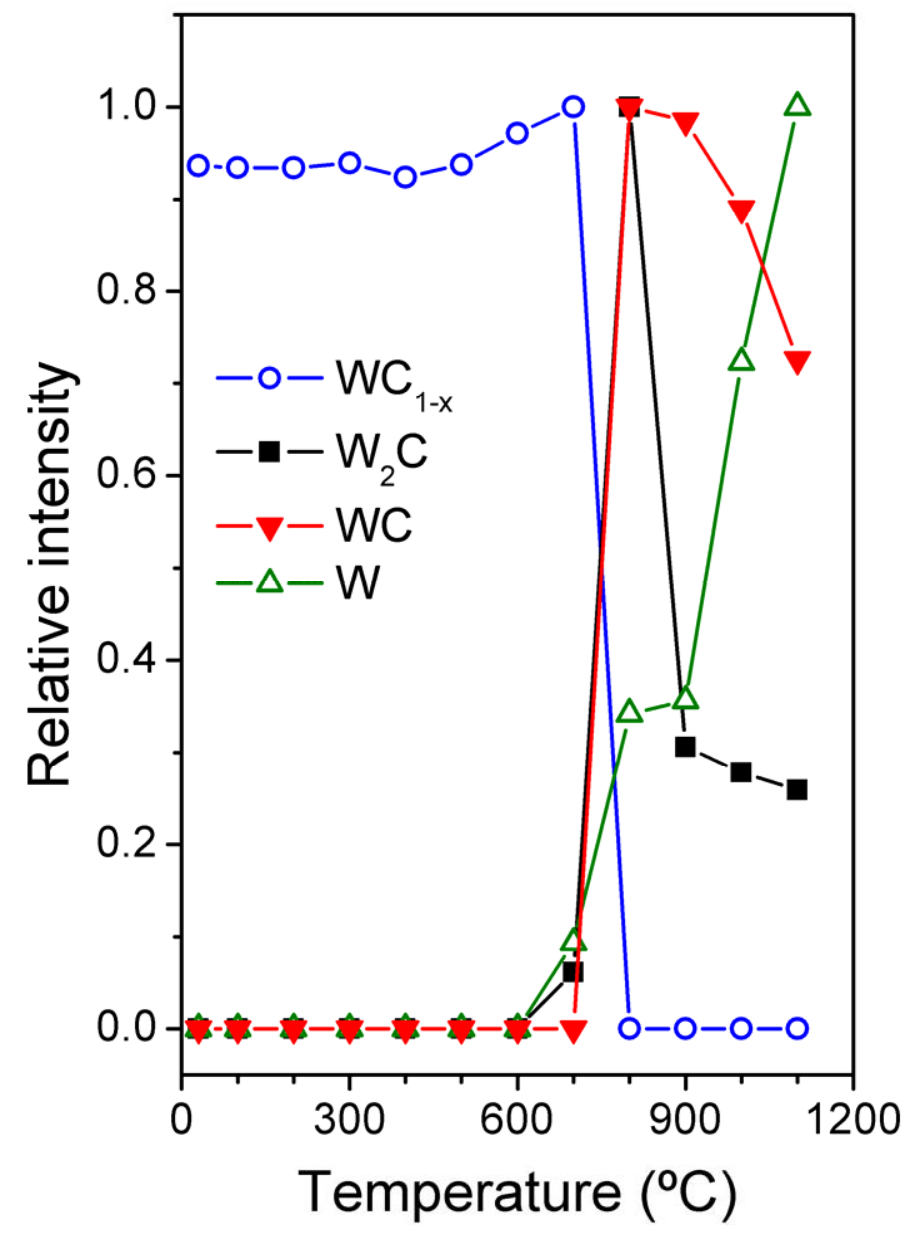




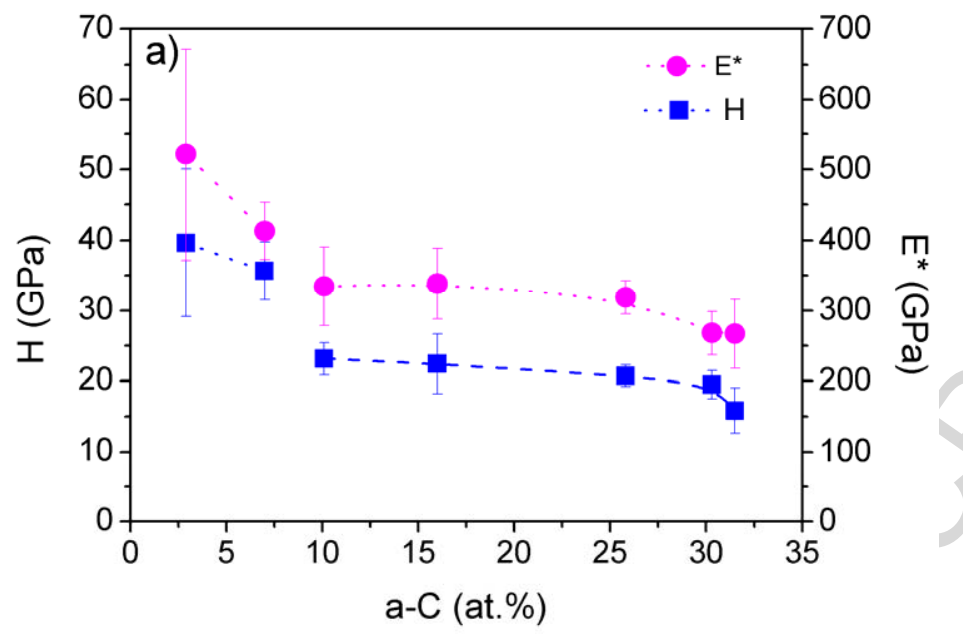




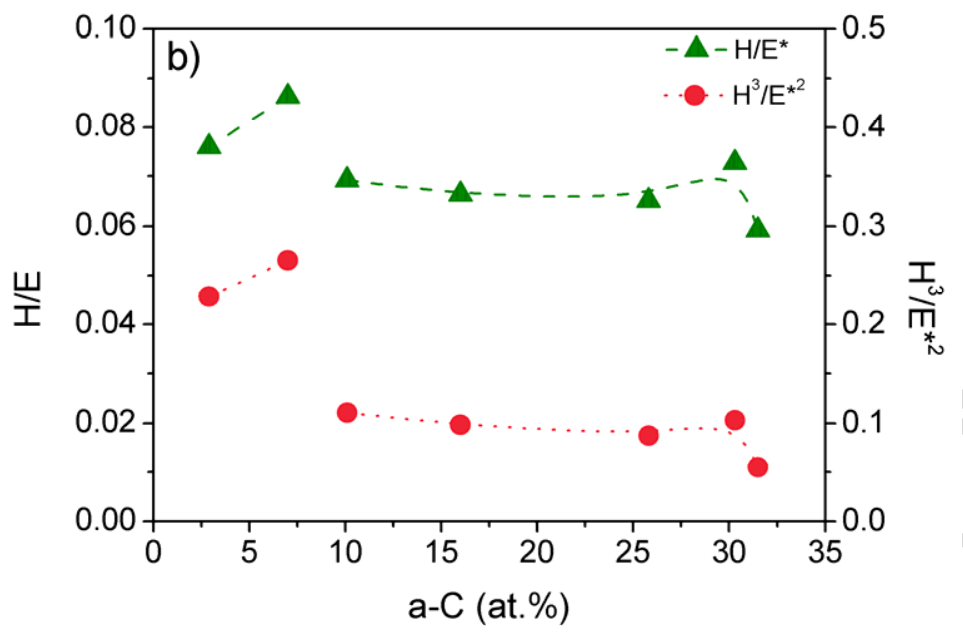




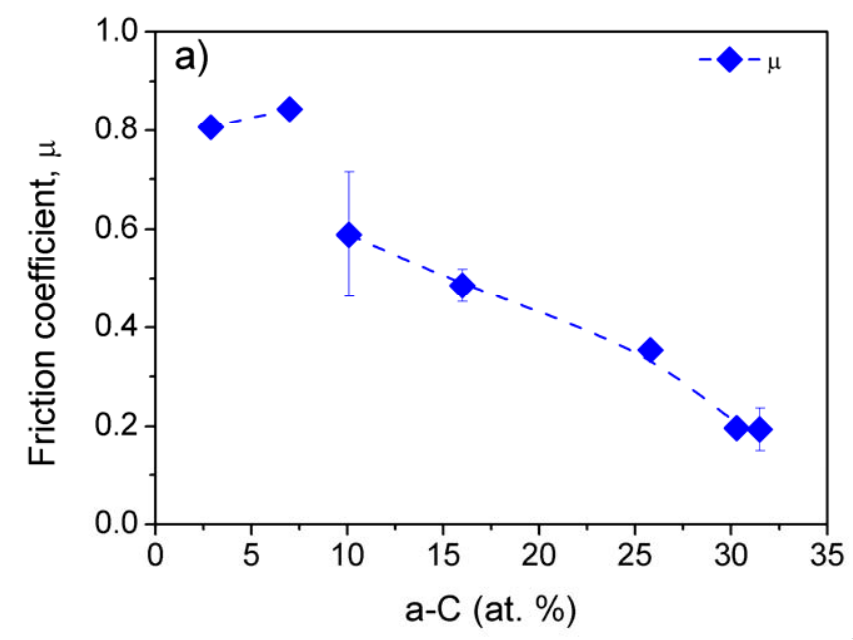




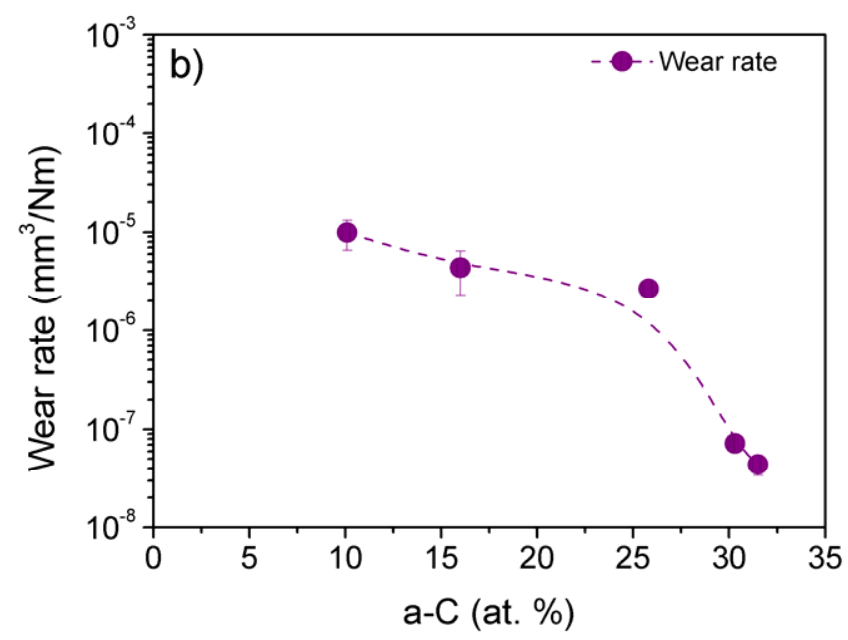


Table 1. Film sputtering conditions, elemental composition by XPS with sputtering and chemical bonding for the WC/a-C samples.

\begin{tabular}{|c|c|c|c|c|c|c|c|c|c|c|}
\hline \multirow[t]{2}{*}{ Film } & \multicolumn{2}{|c|}{$\begin{array}{l}\text { Power applied } \\
\text { (W) }\end{array}$} & \multirow[t]{2}{*}{$R^{\text {a) }}$} & \multirow[t]{2}{*}{$\begin{array}{l}\text { Thickness } \\
(\mu \mathrm{m})\end{array}$} & \multicolumn{3}{|c|}{$\begin{array}{c}\text { Elemental composition } \\
\text { (at. \%) }\end{array}$} & \multicolumn{3}{|c|}{$\begin{array}{c}\text { Chemical bonding } \\
\text { (at. \%) }\end{array}$} \\
\hline & $\mathrm{P}_{\mathrm{C}}$ & $\mathrm{P}_{\mathrm{WC}}$ & & & $\mathrm{W}$ & $\mathrm{C}$ & $\mathrm{O}$ & $\mathrm{W}_{\mathrm{w}-\mathrm{C}}$ & $\mathrm{C}_{\mathrm{C}-\mathrm{W}}$ & $\mathrm{C}_{\mathrm{a}-\mathrm{C}}$ \\
\hline R0 & -- & 250 & $0^{\text {b) }}$ & 0.8 & 63 & 33 & 4 & 66 & 27 & 7 \\
\hline R0.1 & 20 & 250 & 0.1 & 1.3 & 58 & 37 & 5 & 62 & 35 & 3 \\
\hline R0.3 & 70 & 250 & 0.3 & 1.5 & 47 & 50 & 3 & 50 & 40 & 10 \\
\hline R0.5 & 125 & 250 & 0.5 & 1.6 & 40 & 55 & 5 & 44 & 40 & 16 \\
\hline R1 & 250 & 250 & 1 & 2.5 & 32 & 64 & 4 & 35 & 39 & 26 \\
\hline R2 & 300 & 150 & 2 & 1.4 & 28 & 69 & 3 & 31 & 39 & 30 \\
\hline R3 & 450 & 150 & 3 & 1.8 & 27 & 71 & 2 & 30 & 39 & 31 \\
\hline
\end{tabular}

a) $\mathrm{R}$ is defined as $\mathrm{P}_{\mathrm{C}} / \mathrm{P}_{\mathrm{WC}}$ ratio

b) $100 \mathrm{~V}$ Bias applied 
Table 2. Mechanical and tribological properties for the WC/a-C samples.

\begin{tabular}{ccccccccc}
\hline Film & $\mathrm{C}_{\text {total }}$ & a-C & \multicolumn{3}{c}{ Mechanical properties } & \multicolumn{2}{c}{ Tribological properties } \\
\cline { 4 - 8 } & (at.\%) & $($ at.\% $)$ & $\mathrm{H}(\mathrm{GPa})$ & $\mathrm{E}^{*}(\mathrm{GPa})$ & $\mathrm{H} / \mathrm{E}^{*}$ & $\mathrm{H}^{3} / \mathrm{E}^{* 2}$ & $\mu$ & $\mathrm{k}\left(\mathrm{mm}^{3} / \mathrm{Nm}\right)$ \\
\hline R0 & 33 & 7 & $36 \pm 4$ & $413 \pm 40$ & 0.086 & 0.265 & $0.84 \pm 0.01$ & - \\
$\mathrm{R} 0.1$ & 37 & 3 & $40 \pm 10$ & $522 \pm 149$ & 0.076 & 0.228 & $0.81 \pm 0.01$ & - \\
$\mathrm{R} 0.3$ & 50 & 10 & $23 \pm 2$ & $334 \pm 55$ & 0.069 & 0.111 & $0.59 \pm 0.13$ & $9.9 \times 10^{-6} \pm 3.3 \times 10^{-6}$ \\
$\mathrm{R} 0.5$ & 55 & 16 & $22 \pm 4$ & $338 \pm 50$ & 0.066 & 0.099 & $0.49 \pm 0.03$ & $4.4 \times 10^{-6} \pm 2.1 \times 10^{-6}$ \\
$\mathrm{R} 1$ & 64 & 26 & $21 \pm 1$ & $319 \pm 23$ & 0.065 & 0.088 & $0.35 \pm 0.01$ & $2.0 \times 10^{-6} \pm 1.7 \times 10^{-6}$ \\
$\mathrm{R} 2$ & 69 & 30 & $20 \pm 2$ & $268 \pm 30$ & 0.073 & 0.103 & $0.20 \pm 0.01$ & $7.2 \times 10^{-8} \pm 8.6 \times 10^{-9}$ \\
$\mathrm{R} 3$ & 71 & 31 & $16 \pm 3$ & $267 \pm 48$ & 0.059 & 0.055 & $0.19 \pm 0.04$ & $4.4 \times 10^{-8} \pm 1.0 \times 10^{-8}$ \\
\hline
\end{tabular}

